\title{
Temporal Dynamics of Botrytis cinerea and Sclerotinia sclerotiorum in Seed Alfalfa Fields of Southern Alberta, Canada
}

J. Reich, Lethbridge Research and Development Centre, Agriculture and Agri-Food Canada, Lethbridge, AB, T1J 4B1, Canada; and University of Lethbridge, Lethbridge, AB, T1K 6T5, Canada; S. Chatterton, Lethbridge Research and Development Centre, Agriculture and Agri-Food Canada; and D. Johnson, University of Lethbridge

\begin{abstract}
Blossom blight of seed alfalfa (Medicago sativa L.), caused by the fungal pathogens Botrytis cinerea and Sclerotinia sclerotiorum, is a potentially devastating disease on the Canadian Prairies in moist growing seasons. Monitoring the airborne spore concentrations of these pathogens could facilitate disease forecasting in the region. Nineteen seed alfalfa fields in southern Alberta, Canada were assessed throughout the growing seasons of 2014 and 2015. Trace levels of blossom blight symptoms were found in both years; however, plated floret and pod samples indicated that, overall, B. cinerea increased over the growing season whereas S. sclerotiorum decreased. In both seasons, Burkard 7-day volumetric

spore samplers collected daily aerosol samples, and weather stations recorded environmental variables in three fields. Conidia and ascospores collected were quantified each day with a real-time polymerase chain reaction assay. Spore quantification indicated that both $B$. cinerea and $S$. sclerotiorum numbers remained low in July and increased in August. Both species had multiple days with high spore discharge, with seasonal maxima of 21,137 conidia and 2,265 ascospores. Exploratory model development indicated that spore discharge of both fungi is associated with environmental stressors such as large changes in relative humidity or high temperatures on preceding days.
\end{abstract}

Alfalfa (Medicago sativa L.) grown for seed is a lucrative specialty crop, whose production in Canada is concentrated in southern Alberta (CSGA 2014). Blossom blight and stem rot, both caused by the fungal pathogens Botrytis cinerea Pers. and Sclerotinia sclerotiorum (Lib.) de Bary, have been associated with severe losses in alfalfa seed across the Canadian Prairies in moist seasons (Gossen and Platford 1999; Gossen et al. 1997, 1998; Huang et al. 2000). These pathogens produce conidia and ascospores, respectively, which are transported by wind and act as the main infectious units. Airborne spores land on senescent petal tissue, which provides a rich nutrient source for pathogen establishment, and readily spread to infect whole racemes, resulting in reduced seed production (Huang et al. 2000; Olivier et al. 2008).

Several production practices may contribute to the development of blossom blight. First, because the majority of seed alfalfa fields in southern Alberta are irrigated, the additional moisture may contribute to the prolonged humid microclimates that favor the blossom blight pathogens (Broome et al. 1995; Clarkson et al. 2014). Second, alfalfa grown for seed is cultivated as a perennial, and is susceptible to pathogens that can survive between seasons and compound inoculum over years (Hind-Lanoiselet et al. 2005). Sclerotia of $S$. sclerotiorum may remain viable in soil for several years (Adams and Ayers 1979; Coley-Smith and Cooke 1971), meaning that inoculum may build up over years and cause a severe epidemic under prolonged cool, humid conditions (Huang et al. 2000; Samac et al. 2015). Third, alfalfa has a long flowering period, lasting from the beginning of July until mid-August, during which it is most susceptible to infection by blossom blight pathogens (Frank 2003; Samac et al. 2015).

Currently, detection methods for S. sclerotiorum and B. cinerea are based on visual signs of disease (gray or white, fluffy mycelia on blossoms or stems) (Gossen and Platford 1999; Gossen et al.

Corresponding author: S. Chatterton; E-mail: syama.chatterton@agr.g.c.ca

This is LeRDC contribution number 387-16047.

Accepted for publication 28 September 2016.

() Her Majesty the Queen in Right of Canada, as represented by the Minister of Agriculture and Agri-Food Canada
1997; Samac et al. 2015), or on using semiselective media to capture airborne spores or to plate florets for quantifying infection levels (Parker et al. 2014; Turkington and Morrall 1993). The use of agar media, however, requires waiting several days for the fungi to grow to an identifiable stage and a certain level of expertise in fungal identification. This delay in data collection does not allow growers to take preventative action if high disease risk is predicted. Other approaches have involved microscopic identification of pathogens based on spores trapped on an adhesive surface (Carisse et al. 2005; McCartney and Lacey 1991; Qandah and del Río Mendoza 2011; Xu et al. 1995). However, visual methods of identification are difficult when dealing with organisms such as $S$. sclerotiorum and $B$. cinerea, whose spores are morphologically similar to each other and to other species.

A growing body of research has shown that the coupling of aerial monitoring and molecular techniques can result in rapid and reliable quantification of airborne plant pathogens (Carisse et al. 2009; Klosterman et al. 2014; Parker et al. 2014; Rogers et al. 2009), the benefits of which have been reviewed by West and Kimber (2015), West et al. (2008), and Peccia and Hernandez (2006). Due to the sensitivity and specificity of molecular techniques such as quantitative (real-time) polymerase chain reaction ( $\mathrm{qPCR}$ ), substantial advances in understanding daily and seasonal spore release patterns have been made (Almquist and Wallenhammar 2015; Lang-Yona et al. 2012; Luo et al. 2007). In conjunction with environmental and disease intensity monitoring, these data can be used to develop a disease forecasting model whose purpose is to reduce fungicide applications by timing applications when disease risk is high (Carisse et al. 2005; Rodríguez-Rajo et al. 2010; $\mathrm{Xu}$ et al. 2000). Monitoring airborne inoculum levels has been shown to increase the reliability of disease forecasting systems based solely on environmental variables (Carisse et al. 2009; $\mathrm{Xu}$ et al. 2000).

A disease forecasting model for blossom blight in seed alfalfa has not yet been developed, although this pathosystem is a good candidate for such a model. Seed production in southern Alberta is concentrated within a relatively small region, meaning that environmental conditions across fields would be similar and that a disease forecasting model could be implemented for the whole region. Because the infectious units of blossom blight pathogens are primarily airborne, they are conducive to monitoring by aerosol capture (West et al. 2008). Spore discharge patterns of $S$. sclerotiorum and B. cinerea have not been studied in this region and, because the population dynamics 
are unknown, these pathogens are managed primarily by fungicide application (Bardin and Huang 2001; Frank 2003). A robust disease forecasting system would reliably predict when disease pressure is high and alert growers to apply fungicides only when necessary. In addition, knowledge of airborne spore concentrations could help determine the most appropriate times for irrigating because, for pathogens such as $B$. cinerea, germination and infection increase based on moisture and relative humidity levels (Nair and Allen 1993; Williamson et al. 1995).

Therefore, the goals of this research were to (i) survey commercial seed alfalfa fields in southern Alberta to determine the intensity of blossom blight in the region, (ii) quantify temporal changes of airborne inoculum of $S$. sclerotiorum and B. cinerea over the growing season, and (iii) determine whether and to what extent spore release by these fungi is related to environmental conditions.

\section{Materials and Methods}

Field surveys and sample collection. Nineteen commercial seed alfalfa fields were surveyed every 2 weeks during blossoming and pod development (end of June to mid-August) in 2014 to 2015. The fields were located in southern Alberta, Canada, near the towns of Enchant, Rosemary, and Brooks. For each field, 10 sites were sampled in a U-shaped pattern and were at least $20 \mathrm{~m}$ apart from each other and from the field's edge. At each site, 20 stems of alfalfa (approximately $1 \mathrm{~m}$ of row) were assessed for severity and intensity of blossom blight and stem rot. For blossom blight, severity was rated on a scale of 0 to $4(0=$ no florets infected and $1=1$ to $25,2=26$ to $50,3=51$ to 75 , and $4=76$ to $100 \%$ florets infected) and incidence was recorded as the number of racemes out of 20 that had blossom blight symptoms. For stem rot, severity was rated on a scale of 0 to $5(0=$ no infection and $1=<1,2=1$ to $10,3=11$ to $25,4=26$ to 50 , and $5=>50 \%$ of stem infected) and incidence was rated as the number of stems out of 20 showing stem rot symptoms. From each site, racemes were harvested (three each of florets or pods, depending on development of the plants) for processing in the lab. Racemes that had recently been pollinated and showed some petal senescence were preferentially chosen, because they were more likely to be infected by blossom blight pathogens (Huang et al. 2000). A final seed sample, approximately $500 \mathrm{ml}$ in volume, was collected from growers once the crop had been harvested.

Processing floret, pod, and seed samples. Ten florets or pods collected from each of 10 sites per field were surface disinfested (60 s in $0.5 \% \mathrm{NaClO}$ plus two to three drops of Tween 20), triple rinsed with double-distilled water filtered through a $0.22-\mu \mathrm{M}$ filter (Milli-Q Reference Ultrapure Water Purification System; EMD Millipore) immediately prior to surface disinfestation, and dried on a paper towel. Five florets or pods were plated on each of Sclerotinia semiselective medium (SSM) (Edwards and Seddon 2001) and Botrytis semiselective medium (BSM) (Gutierrez and Shew 1998) for each site ( $=50$ florets or pods per medium per field). For the last field collection in late August, seed were extracted from surfacedisinfested pods and surface disinfested using the previous method, and 10 seeds were plated on each of SSM and BSM. Seed obtained after harvest were processed in the same manner, except with the sterilization period extended to $120 \mathrm{~s}$. Twenty seeds were plated on each of five plates of SSM and BSM.

Identification of pathogens from plate culture. Plates were incubated at room temperature in the dark and samples were rated for pathogen incidence at 5 and 7 days. Samples on SSM were positive for S. sclerotiorum if the medium changed from purple to yellow, and if white, fluffy mycelia or sclerotia were present. Color change was not a sufficient criterion because $B$. cinerea also produces oxalic acid, the chemical responsible for the color change, but does not produce white mycelia. Samples on BSM were positive for B. cinerea if the medium changed from pink to brown and also either had (i) extensive hyphal growth ( $>1.5 \mathrm{~cm}$ after 7 days) that was morphologically consistent with the pathogen or (ii) formed conidia. When culture morphology was ambiguous, a stereomicroscope was used to search for formation of microsclerotia on the plant tissue. These criteria were necessary because species of other common fungi, particularly
Alternaria, Penicillium, and Cladosporium spp., grew on the medium and caused a color change from pink to brown. Means and standard errors for the levels (percentage) of floret, pod, and seed infection from field surveys were calculated using the UNIVARIATE procedure in SAS (SAS Institute Inc.).

Previous work in seed alfalfa fields of southern Alberta (Reich et al. 2016) had sequenced parts of the internal transcribed spacer and $\beta$-tubulin gene of several of the presumptive $S$. sclerotiorum and $B$. cinerea field isolates. Although all presumptive $S$. sclerotiorum isolates were correctly identified based on genetic sequences, only about half of the suspected $B$. cinerea isolates were identified as such, and the other half were an unidentified Botrytis sp. To investigate this phenomenon further, sporulating Botrytis cultures were collected from samples on BSM and purified through hyphal transfers on potato dextrose agar. DNA was extracted as described by Reich et al. (2016), and primers specific to the RNA polymerase subunit-II (RPB2) gene were used for PCR amplification, because this region has been used previously in the delineation of Botrytis spp. (Ferrada et al. 2016; Staats et al. 2005). PCR products were sequenced using Genome Quebec sequencing services, and sequences were compared with the GenBank database using a BLASTn search for species identification. In total, 87 isolates and sequences spanning both years and all collection times were collected in this manner.

Collection of airborne ascospores and conidia. In both years, three fields with known histories of blossom blight symptoms were chosen for air sampling. In 2014, the fields were located near Enchant, Brooks, and Rosemary and were chosen so that sampling would represent the main seed-growing regions in southern Alberta. In 2015, the field near Enchant was no longer in production and, instead, a second field near Rosemary was selected. This field was chosen because the grower did not apply fungicides to the crop over the course of the growing season. One Hirst-type, 7-day multivial cyclone sampler (Burkard Manufacturing Co. Ltd.) was placed in each of three fields, with the air intake valve $1.0 \mathrm{~m}$ above the ground and approximately $0.2 \mathrm{~m}$ above the top of the alfalfa canopy at maturity. Each sampler was powered by a $12-\mathrm{V}$ battery, which was attached to a solar panel to maintain charge throughout the sampling period, and sampled air at a rate of 16.5 liters $\mathrm{min}^{-1}$ or approximately $1 \mathrm{~m}^{3} \mathrm{~h}^{-1}$. Due to differences of maximum spore dispersal times between species and between seasons (Jarvis 1962; Qandah and del Río Mendoza 2011), samplers ran continuously throughout the day (00:05 to 23:55 h) for the growing season (mid-June to early September) and vials were collected and replaced each week. Collected vials were stored at $-20^{\circ} \mathrm{C}$ until DNA was extracted.

DNA extraction of aerosols. DNA extraction from frozen samples followed the protocol described by Parker et al. (2014). Briefly, $100 \mu \mathrm{l}$ of cetyltrimethylammonium bromide (CTAB) buffer $(100 \mathrm{ml}$ of $1 \mathrm{M}$ Tris $\mathrm{HCl}$ [pH 8.0], $280 \mathrm{ml}$ of $5 \mathrm{M} \mathrm{NaCl}, 40 \mathrm{ml}$ of $0.5 \mathrm{M}$ EDTA, $20 \mathrm{~g}$ of CTAB, and double-distilled $\mathrm{H}_{2} \mathrm{O}$ to 1 liter) were added to each tube and the tubes were vortexed for $10 \mathrm{~min}$. The tubes were subjected to three freeze-thaw cycles (liquid $\mathrm{N}_{2},-60^{\circ} \mathrm{C}$ ) for $2 \mathrm{~min}$ each, with the final thaw period extended to $30 \mathrm{~min}$. The tubes were then spiked with $10^{6}$ copies of the internal exogenous control TaLTP3 plasmid, described below, followed by DNA extraction using a PowerSoil DNA extraction kit (MoBio Laboratories Inc.).

Internal control plasmid and normalization. A plasmid containing a lipid transfer protein from wheat (Triticum aestivum) was obtained from Dr. Nora Foroud (Agriculture and Agri-Food Canada, Lethbridge, AB, Canada) for use as an internal control. The plasmid, TaLTP3, was chosen because DNA from wheat is unlikely to be found in the aerosol samples and primers targeting this gene would not amplify fungal DNA. Prior to extraction, $10^{6}$ copies of the TaLTP3 plasmid were added to each sample to account for extraction efficiencies and false negatives and to act as a normalizing agent. Because the variation in extraction efficiency may be relatively high (Hospodsky et al. 2010; Wagner et al. 2015), all samples were normalized to the internal control prior to statistical analysis. For normalizing, the geometric mean of plasmid copies quantified by qPCR was calculated from all technical replicates for each set of DNA extractions (Anders and Huber 2010; Dillies et al. 2013). For each sample, the median 
number of plasmid copies quantified was then divided by the geometric mean to calculate a normalizing factor. The number of spores detected in each sample was then multiplied by its unique normalizing factor.

Multiplex qPCR. Originally, a previously described multiplex assay for S. sclerotiorum and B. cinerea (Reich et al. 2016) was to be extended to include the TaLTP3 primers. However, due to poor performance of this triplex reaction, pathogen DNA was quantified in two separate reactions. Thus, reactions to quantify S. sclerotiorum and $B$. cinerea DNA were run separately, and each species-specific reaction was multiplexed with primers or probe to detect the internal control plasmid (Table 1). Each $25-\mu 1$ multiplex reaction contained $12.5 \mu \mathrm{l}$ of $2 \times$ Environmental Master Mix (Life Technologies), either $300 \mathrm{nM}$ SsIGS_5 or Bc3 primer pairs and $300 \mathrm{nM}$ TaLTP3 primer pairs, $200 \mathrm{nM}$ each probe, and $4 \mu \mathrm{l}$ of DNA. Reactions were performed in technical triplicates in a CFX96 Touch Real-Time PCR Detection System (Bio-Rad) with the following cycle conditions: $95^{\circ} \mathrm{C}$ for $10 \mathrm{~min}$ followed by 40 cycles of $60^{\circ} \mathrm{C}$ (for $\mathrm{B}$. cinerea) or $58^{\circ} \mathrm{C}$ (for S. sclerotiorum) for $1 \mathrm{~min}$ and $95^{\circ} \mathrm{C}$ for $15 \mathrm{~s}$. All primers (salt purified) and probes (high-performance liquid chromatography purified) were ordered from Eurofins MWG Operon LLC.

Conidia and ascospore production for standard curves. To produce conidia, B. cinerea (isolate LRC 2421, Lethbridge Research Centre culture collection) was grown on $2 \%(\mathrm{wt} / \mathrm{vol})$ malt extract agar for 7 days in the dark at room temperature. Cultures were then exposed to near-UV light ( $12 \mathrm{~h} /$ day and $12 \mathrm{~h}$ /night) until conidia developed, approximately 10 days. Conidia were harvested by flooding the plates with sterile distilled water (SDW) and filtering through four layers of cheesecloth. The suspension was adjusted to $3.2 \times$ $10^{6}$ conidia $\mathrm{ml}^{-1}$ using a hemocytometer. To produce ascospores of S. sclerotiorum, the method described by Huang and Kozub (1989) was followed, with some modification. Briefly, S. sclerotiorum (isolate LRC 2148, Lethbridge Research Centre culture collection) sclerotia were conditioned at $10^{\circ} \mathrm{C}$ for 10 weeks and transferred to petri dishes containing sterilized Cornell mix, and the petri dishes were flooded with SDW. The cultures were incubated at room temperature under constant light for 2 to 3 weeks; water levels were maintained at the flooded state during this period by adding SDW to the petri dishes every 3 to 4 days. After approximately 2 weeks, ascospores were harvested by lifting the lid slightly off the petri dish, which created a puff of ascospores from the apothecia that would attach to the lid. This harvesting procedure was repeated over a number of days to obtain enough ascospores for standard curve assays. To collect the ascospores, the lid was flooded with SDW and the ascospore concentration was adjusted to $3.6 \times 10^{6}$ ascospores $\mathrm{ml}^{-1}$ using a hemocytometer.

Creating standard curves. To create the standard curves, spores of each pathogen were serially diluted in sheared salmon sperm DNA (Invitrogen, Life Technologies) at $10 \mathrm{ng} / \mu \mathrm{l}$ to simulate matrix effects (Carisse et al. 2009) and DNA was extracted from the dilutions. This approach quantifies aerosol samples more accurately than extracting DNA first and serially diluting the DNA (An et al. 2006; Diguta et al. 2010; Luo et al. 2007). The serial dilutions were 10 -fold from $10^{5}$ to $10^{1}$ spores $\mathrm{ml}^{-1}$, with additional twofold dilutions at the $10^{3}$ and $10^{2}$ concentrations. Each suspension $(100 \mu \mathrm{l})$ was pipetted into $1.5-\mathrm{ml}$ centrifuge tubes, and DNA extractions were performed as described previously. Thus, the extractions were from $3.2 \times 10^{4}, 3.2 \times 10^{3}$,
$3.2 \times 10^{2}, 1.6 \times 10^{2}, 32,16$, and 3.2 conidia for $B$. cinerea and $3.6 \times 10^{4}, 3.6 \times 10^{3}, 3.6 \times 10^{2}, 1.8 \times 10^{2}, 36,18$, and 3.6 ascospores for $S$. sclerotiorum. The extractions were repeated three times for each conidia or ascospore concentration and, following extraction, were mixed to create the DNA stock for the standard curve. This DNA was run in technical triplicates and included with the field samples in each 96-well reaction plate to produce a standard curve specific for each run.

Aerosol spore quantification and data quality control. Median cycle threshold $\left(C_{t}\right)$ values of each triplicate $\mathrm{qPCR}$ sample were used for calculating spore number. Spore numbers are reported as the total number of conidia or ascospores detected in a single day, and were not normalized to spores per hour or spores per cubic meter. Samples were excluded from analysis if their wells had no or very low $(<1,000$ copies) amplification of the internal control plasmid. Any sample that had a detected quantity of spores $<32$ or 36 - the limits of detection for B. cinerea and $S$. sclerotiorum, respectively-were considered zero.

Collection of weather data. WatchDog Mini (model 2450) weather stations (Spectrum Technologies Inc.) were mounted on PVC pipe and placed at $0.8 \mathrm{~m}$ above ground level in each of the fields containing spore samplers. A leaf-wetness (LW) sensor was placed within the canopy at $0.4 \mathrm{~m}$ above ground level, and a rain gauge was placed $1.0 \mathrm{~m}$ above ground level. Because seed alfalfa fields are irrigated, the rain gauge collected precipitation (Precip) from both irrigation and natural rainfall events. Temperature (T), Precip, relative humidity (RH), LW, and dew point (DP) were recorded hourly, and $\mathrm{T}$ and RH were used to calculate vapor pressure deficit (VPD), as described by Xu et al. (2000). Daily maxima, minima, and means were calculated for all variables. Evapotranspiration (ET) data were obtained from the Alberta Irrigation Management Model online files (http://www.imcin.net/aimm-files/aimm-et.htm) for the daily ET of alfalfa at Enchant, Brooks, and Rosemary for the respective study fields at these locations. Wind was not recorded as a variable because several previous studies found it was rarely a limiting factor in spore release and, therefore, rarely correlated with $B$. cinerea or $S$. sclerotiorum spore release (Rodríguez-Rajo et al. 2010; Xu et al. 1995).

Statistical analysis and model development. An exploratory approach was used to model the release of spores in relation to environmental variables. Several response variables were calculated from the raw spore data for each of $S$. sclerotiorum and $B$. cinerea: one continuous variable, $\log$ Spore (calculated as $\log [$ number of conidia or ascospores +1$]$ ), and three binary variables: SporeY/N (summarized as presence $[=1]$ or absence $[=0]$ of each spore type on a given day), StartSpore (indicating the start of a multiday sporulation event; a sporulation event was considered to start $[=1]$ on a given day if spores were detected on that day and no spores were detected on the previous day; all subsequent days following the start of a sporulation event were coded as 0), and Spore $>100$ (an arbitrary threshold cut-off of 100 spores/day, where days on which more than 100 spores were released were coded as 1 and days on which less than 100 spores were released were coded as 0) (Table 2).

Relatively few studies report statistical approaches to describe the release of B. cinerea or S. sclerotiorum spores, although several studies use descriptive analyses relating spore release to environmental variables (Bourdôt et al. 2001; Hartill 1980; Inch et al. 2005; Luo

Table 1. List of primers and probes used in quantitative (real-time) polymerase chain reaction assays

\begin{tabular}{|c|c|c|c|c|}
\hline Target & Reference & Primer, probe & Sequence $\left(5^{\prime}-3^{\prime}\right)$ & Amplicon size (bp) \\
\hline \multirow[t]{3}{*}{ Sclerotinia sclerotiorum } & Reich et al. 2016 & SsIGS_5F & CCTACATTCTACTTGATCTAGTA & 79 \\
\hline & & SsIGS_5R & GTTGGTAGTTGTGGGTTA & \\
\hline & & SsIGS_5P & [Cу5]ACTTCCAAGTGAATACCAGWGATAA[BHQ2] & \\
\hline \multirow[t]{3}{*}{ Botrytis cinerea } & Suarez et al. 2005 & $\mathrm{Bc} 3 \mathrm{~F}$ & GCTGTAATTTCAATGTGCAGAATCC & 95 \\
\hline & & $\mathrm{Bc} 3 \mathrm{R}$ & GGAGCAACAATTAATCGCATTTC & \\
\hline & & $\mathrm{Bc} 3 \mathrm{P}$ & [FAM]TCACCTTGCAATGAGTGG[BHQ1] & \\
\hline \multirow[t]{3}{*}{ TaLTP3 (plasmid) } & Foroud 2011 & TaLTP3-178F & GCAGGTGGACTCCAAGCTC & 143 \\
\hline & & TaLTP3-320R & GGCACCTGCACGCTATCT & \\
\hline & & TaLTP3-232P & [HEX]CTCGATCAGCAAGGAGTGCT[BHQ1] & \\
\hline
\end{tabular}


et al. 2007; McCartney and Lacey 1991; Parker et al. 2014). As a result, we used two broad approaches for choosing predictor variables. First, a cursory literature review was performed to determine environmental variables that previous research had implicated in the spore release of $B$. cinerea, $S$. sclerotiorum, and closely related or similarly dispersed fungi. Second, graphical analysis, involving charts of daily spore release overlaid by different climactic variables, was performed to visually assess possible environment-spore release relationships. The majority of studies assessed in the literature review showed a marked diurnal release of spores, and many implicated RH (Clarkson et al. 2003; Qandah and del Río Mendoza 2011), VPD (Xu et al. 1995), or sudden changes in RH (Jarvis 1962; Sutton et al. 1978) in these releases. Thus, while we included data from all variables measured, our statistical analysis focused on permutations of RH and VPD (e.g., the maximum change in RH or VPD over a 3-h period in each day). To assess the possible effect of temporal delay on spore release, all variables for $t, t-1$, and $t-2$, where $t$ represents the day, were also tested, for a total of 123 variables per spore data point (Table 2). Only the significant variables are reported here. All statistical analysis was performed in JMP 12 (SAS Inc.).

Single-variable models for each of the variables were tested in the Fit Model platform for each field-year and for all data combined, with the exception of Brooks in 2014. For Brooks 2014, single-variable models were not tested because there were too few data points for adequate analysis due to spore sampler malfunctions. However, the data points for this field and year were included for the analysis on all data combined. For the single-variable models, the coefficients of variables that contributed significantly to explaining the data compared with the intercept-only model (identified as a significant log-likelihood test for continuous variables or a significant Pearson $\chi^{2}$ test for categorical variables, $\alpha=0.05$ ) were recorded to investigate trends across fields and years. The two response variables (Spore $\mathrm{Y} / \mathrm{N}$ and Spore $>100$ ) that had the greatest number and magnitudes of significant predictor variables were used for the following procedure: Predictor variables that were identified as significant predictors from the first step were included in a logistic regression forward stepwise selection procedure that minimized the Bayesian Information Criterion (BIC) (Neath and Cavanaugh, 2012), using the Fit Model platform. Unique models for each spore type for each field-year and for pooled data were generated in this manner. Forward stepwise regression and a minimum BIC were used to select models because preliminary analysis indicated that this method provided the most parsimonious models when compared with backward or mixed stepwise regression approaches.

The models were then run against the original data, and the area under the receiver operating characteristic curves (AUC) was used to assess the specificity and sensitivity of each model in predicting spore-release events. Receiver operating characteristic (ROC) curves are frequently used to test the reliability of models involving binary outcomes, such as presence or absence of species in ecological literature (Jiménez-Valverde 2012; Pearce and Ferrier 2000; Thuiller et al. 2003), diseased or healthy patients in medical and epidemiological literature (Brooker et al. 2002; Greiner et al. 2000; Swets 1988), and, to a lesser extent, above or below inoculum threshold levels in plant pathological literature (Carisse et al. 2005, 2009). ROC curves plot the sensitivity (the proportion of correctly identified events or cases) against 1 - specificity (where specificity is the proportion of correctly identified nonevents or noncases). The area below the ROC curve is a metric of the predictive ability of the model: an area of 0.5 indicates that the model predicts no better than chance, while an area of 1.0 indicates that the model perfectly predicts all events. An early description of ROC curves (Swets 1988) suggested that an AUC between 0.5 and 0.7 represents poor model accuracy, an area between 0.7 and 0.9 represents moderate model accuracy, and an area $>0.9$ represents high model accuracy.

Because this analysis was considered primarily exploratory, no variables were forced into the models when performing the forward stepwise procedures. In addition, validation of the models was not performed.

\section{Results}

Identification of pathogens from plate cultures. Of the 87 presumptive $B$. cinerea isolates that were sequenced using RPB2 primers and compared with sequences in the National Center for Biotechnology

Table 2. Weather (predictor) and response variables used in multiple logistic regression analyses to determine best fit model for release of ascospores or conidia of Sclerotinia sclerotiorum or Botrytis cinerea, respectively, in relation to environmental variables

\begin{tabular}{|c|c|}
\hline Variable & Definition \\
\hline \multicolumn{2}{|l|}{ Relative humidity (RH) } \\
\hline DiffRH_1d, DiffRH_2d & Difference between maximum (max) and minimum $(\min ) \mathrm{RH}$ on day $t-1$ or $t-2$ \\
\hline RH80_0d & Average $\mathrm{RH}$ is less than $80 \%$ on day $\mathrm{t}$ \\
\hline RH2hMin_1d, RH2hMin_2d & $\begin{array}{l}\left.\text { Min difference in RH (negative, calculated as [RH at } h_{\mathrm{o}}\right]-\left[\mathrm{RH} \text { at } h_{0-2}\right] \text {, where } h \text { is the hour of the day) over } \\
\text { a 2-h period on day } t-1 \text { or } t-2\end{array}$ \\
\hline RH3hMin_Od, RH3hMin_1d, RH3hMin_2d & As for RH2hMin but over a 3-h period on day $\mathrm{t}, t-1$, or $t-2$ \\
\hline RH3hMax_Od & Max (positive) difference in $\mathrm{RH}$ over a 3-h period at $\mathrm{t}$, calculated as for $\mathrm{RH} 2 \mathrm{hMin}$ \\
\hline RH70_0d, RH70_1d, RH70_2d & Average $\mathrm{RH}$ is less than $70 \%$ at $\mathrm{t}, t-1$, or $t-2$ \\
\hline DelRH10_1d & Difference between average $\mathrm{RH}$ between days $\mathrm{t}$ and $t-1$ is greater than 10 percentage points, on day $t-1$ \\
\hline \multicolumn{2}{|r|}{ - } \\
\hline ET_2d & ET at day $t-2$ \\
\hline \multicolumn{2}{|l|}{ Temperature } \\
\hline MinT_1d, MinT_2d & Min temperature at day $t-1$ or $t-2$ \\
\hline MaxT_2d & Max temperature at day $t-2$ \\
\hline AveT_2d & Average temperature at day $t-2$ \\
\hline \multicolumn{2}{|l|}{ Vapor pressure deficit } \\
\hline DiffVPD_0d, DiffVPD_1d & Difference between max and min VPD on day $\mathrm{t}$ or $t-1$ \\
\hline DelVPD2_0d, DelVPD3_0d, DelVPD5_1d & Difference between the average VPD of day $\mathrm{t}$ and $t-1$ is less than $-2,-3$, or $-5 \mathrm{mmHg}$ on days $\mathrm{t}$ or $t-1$ \\
\hline VPDMin_Od & Min VPD on day $\mathrm{t}$ \\
\hline \multicolumn{2}{|l|}{ Precipitation and dew point } \\
\hline PrecipY/N_1d & Precipitation observed $(\mathrm{Y})$ or not $(\mathrm{N})$ on day $t-1$ \\
\hline DPMin_2d- & Min recorded dew point on day $t-2$ \\
\hline \multicolumn{2}{|l|}{ Response variables } \\
\hline LogSpore & $\log _{10}($ no. conidia or ascospores +1$)$ \\
\hline SporeY/N & Presence $(=1)$ or absence $(=0)$ of each spore type on a given day \\
\hline StartSpore & $\begin{array}{l}\text { Sporulation event }(=1) \text { on a given day if spores were detected on that day and no spores were detected on } \\
\text { the previous day }- \text { all subsequent days following the start of a sporulation event were coded as }(=0)\end{array}$ \\
\hline Spore $>100$ & $\begin{array}{l}\text { Days on which more than } 100 \text { spores were released }(=1) \text { and days on which less than } 100 \text { spores were } \\
\text { released }(=0)\end{array}$ \\
\hline
\end{tabular}


Information database, 35 isolates $(40 \%)$ were identified as $B$. cinerea, $17(20 \%)$ were identified as $B$. prunorum, and the remaining $35(40 \%)$ were unresolved or unknown Botrytis spp. When pure genomic DNA from a subset of these cultures was tested using with the qPCR assay for $B$. cinerea, only DNA from the $B$. cinerea isolates was amplified and all other species were not, which indicates that only conidia of $B$. cinerea were quantified in the field samples.

Field surveys and floret, pod, and seed plating. In both 2014 and 2015, alfalfa began blossoming by the beginning of July, with the first pods forming by mid-July. By the middle of August, most of the racemes had reached the pod stage. Field surveys revealed only trace signs of blossom blight and stem rot incidence and severity for both years; therefore, categorical ratings of severity are not presented (Reich and Chatterton 2015). Samples that were plated, however, showed higher levels of infection (Table 3). In general, for both years, $S$. sclerotiorum incidence was greatest (11 to $13 \%$ of florets) in the first sampling periods and decreased steadily to the last sampling period (4\% of pods); conversely, for both years, $B$. cinerea incidence was low (4 to $5 \%$ of florets) in the first sampling periods, peaked ( 6 to $10 \%$ of florets and pods) in the middle of the season, and decreased in the last sampling period ( 2 to $6 \%$ of pods). The fields containing the spore samplers exhibited similar trends for both pathogens, and overall disease incidence was greater than the average in these fields (Figs. 1 to 3 ).

qPCR standard curves and sample inclusion or exclusion. Because quantification of DNA was generally unreliable (i.e., greater variance in $\mathrm{Ct}$ values) for DNA extracted from fewer than 32 and 36 conidia and ascospores (equivalent to DNA of approximately 1 spore/reaction), these were considered to be the limits of detection. Efficiencies ranged from 94 to $110 \%$ for S. sclerotiorum (Fig. 4A) and from 92 to $103 \%$ for B. cinerea (Fig. 4B); $r^{2}$ values were $>0.96$ for all standard curves.

The internal control plasmid was amplified from most of the field spore samples and the $\mathrm{Ct}$ values clustered around the same value, indicating similar extraction and amplification efficiencies among DNA extractions and samples. From both years, 28 samples showed poor or no amplification of the internal control and were excluded from analysis; a further 21 sample days were lost due to malfunctioning of the spore samplers. Thus, in total, there were 375 days with spore data.

Spore discharge and environmental conditions. Temporal discharge patterns and weather (Precip and mean daily VPD) data for each of the three fields surveyed in 2014 and 2015 are presented in Figures 1 to 3 . Overall, 2014 was much wetter than average for the region, with numerous rainfall events in June leading to flooding in some areas, and frequent precipitation again in August (AAFC 2015). Conversely, 2015 was hotter and dryer than average, with several locations in southern Alberta recording record low Precip levels (AAFC 2016). Daily averages of T and RH for 2014 and 2015 recorded by the WatchDog Mini weather stations are given in Figure 5. These differences were not reflected in overall disease intensities for the region, which were similar between seasons (Table 3). VPD patterns were also highly similar among fields (Figs. 1 to $3 \mathrm{E}$ ) within years, despite certain incongruities in other environmental factors such as Precip. In 2015, the field near Brooks experienced greater fluctuations in VPD than other fields and years, indicating that this location and year were hotter and drier than the others.

Although total numbers of ascospores quantified in 2015 were lower than in 2014, the total number of conidia quantified was similar between years (Figs. 1 to 3A). In general, temporal release patterns appeared similar for both pathogens across all fields in both years. Relatively few conidia $(<200)$ and ascospores $(<100)$ per day were quantified during the first 3 weeks in July but, by the last week (e.g., 24 July), most fields in both years showed significantly larger (>200 spores/day) spore discharge events. These larger discharge events tended to continue frequently throughout August. Thus, most conidia and ascospores were released in August at the pod development stage and when relatively few florets were out. The greatest number of conidia quantified in each year was 11,790 on 18 August 2014 (Enchant) and 4,509 on 27 August 2015 (North Rosemary). The greatest number of ascospores quantified in each year was 6,701 on 18 August 2014 (Enchant) and 635 on 24 August 2015 (South Rosemary). On 8 August 2014, a severe hail storm damaged the crop in North Rosemary. The number of ascospores quantified in this field peaked on the days immediately following this storm (Fig. 2A), possibly indicating that ascospores could now escape more readily from the thinned canopy.

For all of the fields containing spore samplers in both years, floret infection by $S$. sclerotiorum peaked by mid-July, prior to any large ascospore-release events, and sharply declined thereafter (Figs. 1 to 3B). The notable exception to this trend was the Brooks field in 2015, which showed an increase in pod infection levels throughout the season (Fig. 1B). Florets and pods infected by $B$. cinerea exhibited greater variability in temporal patterns. In some cases, a similar pattern was observed to that of S. sclerotiorum (e.g., North Rosemary in 2015; Fig. 2B and C); in other instances, floret and pod infection increased throughout the season, coinciding with increased conidial levels (e.g., Enchant, Brooks, and North Rosemary in 2015; Figs. 1 to 3C). In other fields, however, very low levels of infection by $B$. cinerea were observed throughout the season, even in the presence of high concentrations of conidia (e.g., Brooks in 2015; Fig. 1C).

Model development. When data across fields and years were pooled, the log (number of spores) of conidia and ascospores were highly correlated ( $r=0.679, P<0.0001$; data not shown), suggesting that their release may be associated with similar environmental conditions. This hypothesis was supported by the modeling results, which indicated the same direction of influence for similar environmental variables for both conidia and ascospores (data not shown). From single-variable models, several trends emerged. In general, both conidia and ascospore release were positively correlated with environmental stresses (maximum $\mathrm{T} 1$ or 2 days before release, average $\mathrm{RH}<70 \%$ on the day before release, and high maximum VPD or

Table 3. Mean incidence of blossom blight pathogens on floret, pod, and seed samples from seed alfalfa fields in southern Alberta in 2014 and $2015^{\mathrm{a}}$

\begin{tabular}{|c|c|c|c|c|c|c|}
\hline \multirow[b]{2}{*}{ Date } & \multicolumn{2}{|c|}{ Florets infection (\%) } & \multicolumn{2}{|c|}{ Pods infection (\%) } & \multicolumn{2}{|c|}{ Seed infection $(\%)$} \\
\hline & Bc & Ss & Bc & Ss & $\mathbf{B c}$ & Ss \\
\hline \multicolumn{7}{|l|}{2014} \\
\hline 3-5 July & $4.5(0-18)$ & $11.8(2-28)$ & - & - & - & - \\
\hline 21-24 July & $3.8(0-14)$ & $12.0(0-34)$ & $1.6(0-8)$ & $11.6(0-36)$ & - & - \\
\hline 4-6 August & $9.7(0-26)$ & $7.8(0-40)$ & $6.4(0-22)$ & $8.5(0-26)$ & - & - \\
\hline 18-20 August & - & - & $5.6(0-22)$ & $4.0(0-16)$ & $0.4(0-3)$ & $1.1(0-17)$ \\
\hline \multicolumn{7}{|l|}{2015} \\
\hline 30 June-3 July & $3.9(0-24)$ & $13.0(0-50)$ & - & - & - & - \\
\hline 15-17 July & $5.6(0-14)$ & $9.1(0-36)$ & $3.4(0-16)$ & $8.5(0-40)$ & - & - \\
\hline 28-31 July & $8.7(0-18)$ & $4.0(0-24)$ & $7.3(0-18)$ & $6.6(0-20)$ & - & - \\
\hline 13-18 August & - & - & $2.3(0-10)$ & $3.8(0-32)$ & $0.1(0-1)$ & $0.1(0-1)$ \\
\hline
\end{tabular}

${ }^{\text {a }}$ Data are the means of samples collected from 10 sites from 19 fields at each collection time. Samples were surface disinfested and plated on semiselective media for pathogen detection and identification. $\mathrm{Bc}=$ Botrytis cinerea, $\mathrm{Ss}=$ Sclerotinia sclerotiorum, and -indicates that no plant samples were collected for the period specified. Numbers within parentheses indicate minimum to maximum percentage infected. Data for 2014 from Reich and Chatterton (2015). 
ET values 1 or 2 days before release) and sudden changes in the environment (larger increases and decreases in RH or VPD over 2- or 3-h periods 1 or 2 days before spore release). Releases tended to be negatively correlated with high humidity (high minimum $\mathrm{RH}$ values or low VPD values) of the previous 1 or 2 days and precipitation on the previous day.

The models unique to each field and to pooled data determined by multiple logistic regression for response variables Spore $\mathrm{Y} / \mathrm{N}$ and Spore $>100$ are presented in Tables 4 and 5. Overall, model variables changed considerably between spore type, year, and field, although the overall performance of models for individual fields was often high, as determined by the area under the ROC curve (AUC $>0.8$ frequently and AUC $>0.9$ in some cases). When data were pooled and analyzed together, most models found a single variable, the difference in maximum and minimum RH of the day before, to be the only significant variable; and, in most cases, the performance of these models was much poorer (AUC $<0.7$ for most models) than those models unique to each field.

\section{Discussion}

This study was designed to provide foundation knowledge and assessment for a disease forecasting system for blossom blight
Brooks 2014

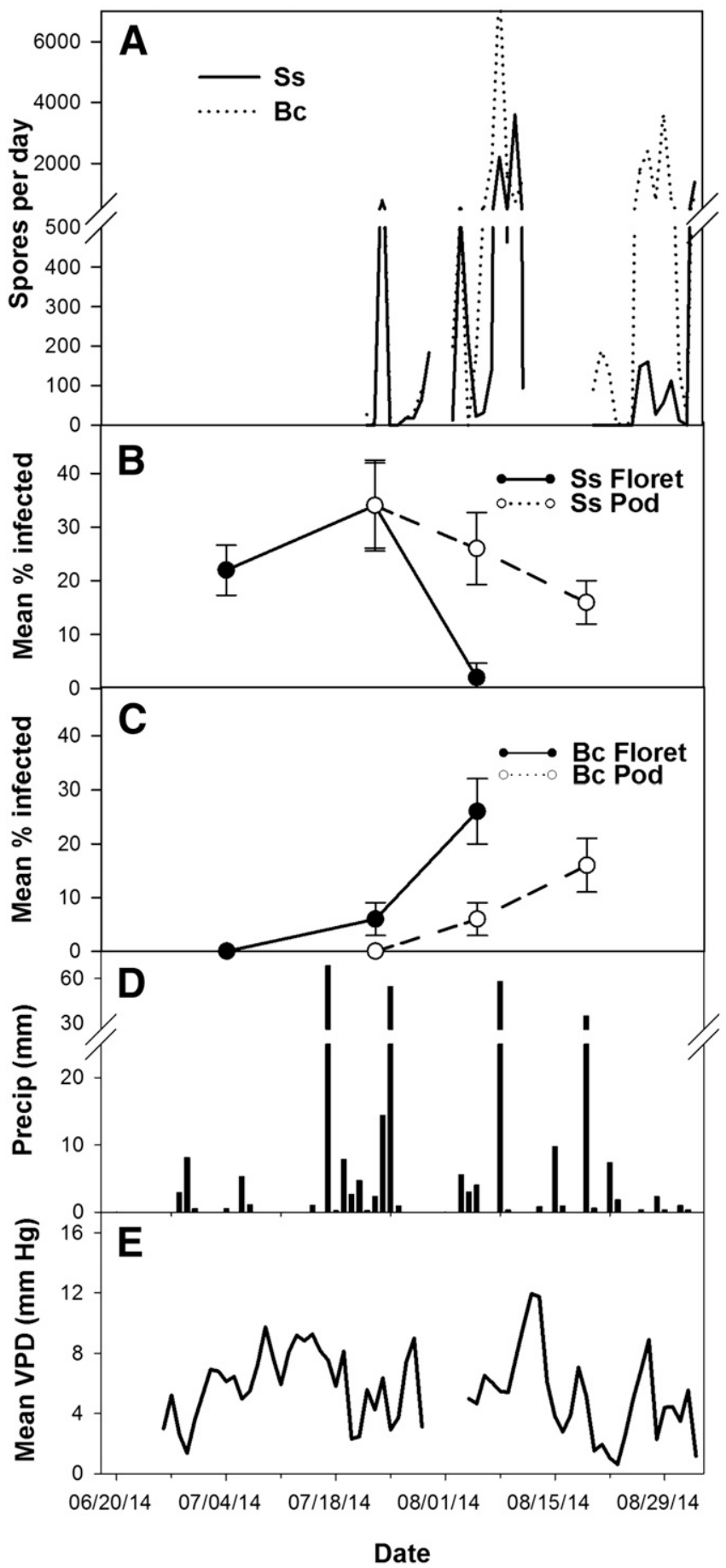

\section{Brooks 2015}

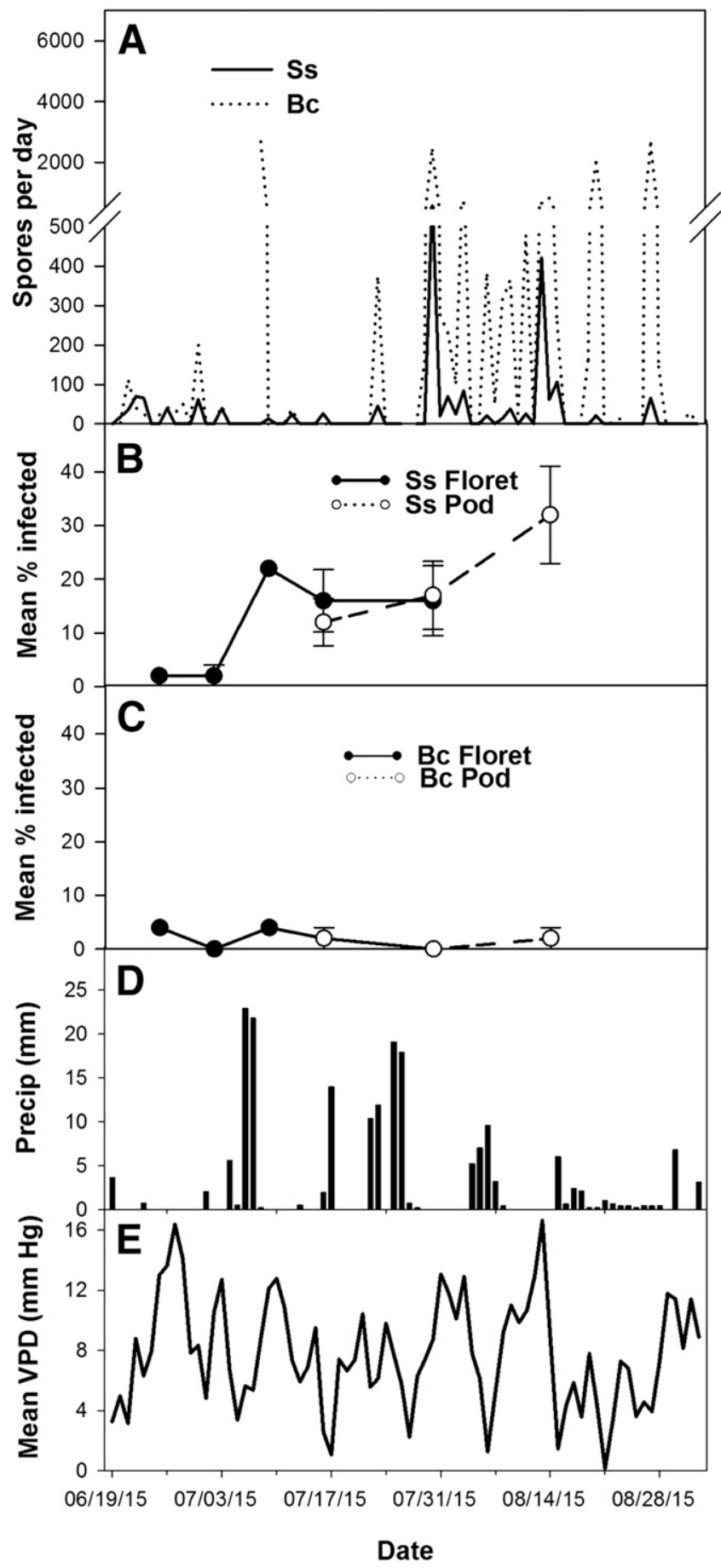

Fig. 1. Temporal discharge of A, Sclerotinia sclerotiorum (Ss) ascospores and Botrytis cinerea (Bc) conidia quantified by quantitative (real-time) polymerase chain reaction; B and $\mathbf{C}$, incidence of pathogens on florets and pods surface disinfested and plated on Sclerotinia semiselective medium and Botrytis semiselective medium; and D and $\mathbf{E}$, associated precipitation and vapor deficit levels in the Brooks field over two growing seasons. 
pathogens $S$. sclerotiorum and B. cinerea in seed alfalfa fields of southern Alberta. Because very low disease levels were observed in field surveys over the 2014 and 2015 season, correlating inoculum or environmental variables with disease intensity was not possible. These results may be confounded by several uncontrolled variables, including the cultivar of alfalfa grown in each field and the fungicide regime (among other management practices) employed by each grower. With the exception of the South Rosemary field in 2015, all sampled fields received one or more fungicide applications according to different schedules throughout the season. If the fungicides were effective, the disease intensities observed in each field may not accurately reflect the true disease pressure in the absence of fungicide, while airborne inoculum levels may not reflect true potential inoculum levels. Nevertheless, floret and pod samples collected and plated on semiselective media showed variability in pathogen inoculum among fields and sampling dates, which could prove more useful than observed disease intensity in developing a disease model (Xu et al. 2000).

In general, according to plated samples, over both the 2014 and 2015 seasons, the presence of $B$. cinerea on plant parts increased throughout the growing season, while $S$. sclerotiorum declined (Table 3). The data collected here are similar to other surveys for

\section{N. Rosemary 2014}

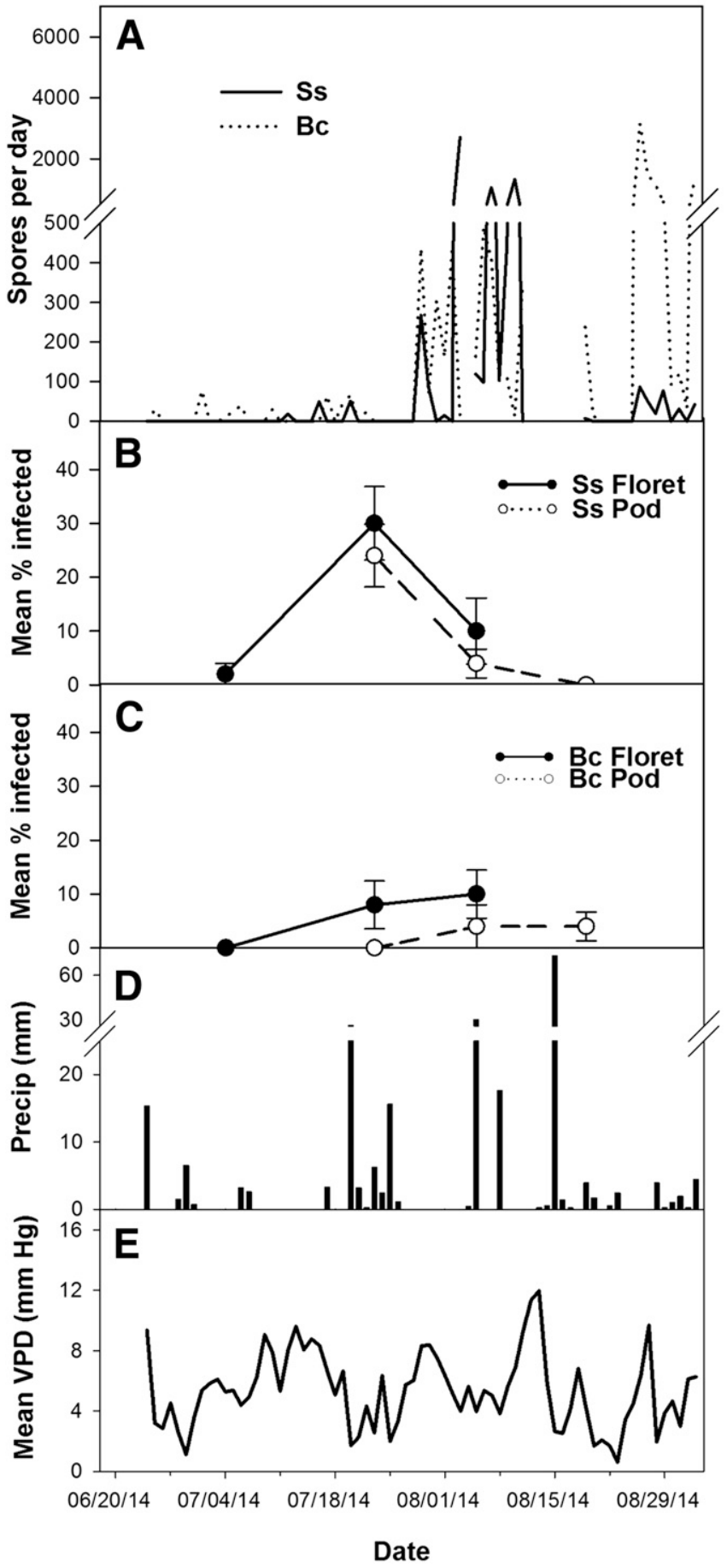

N. Rosemary 2015

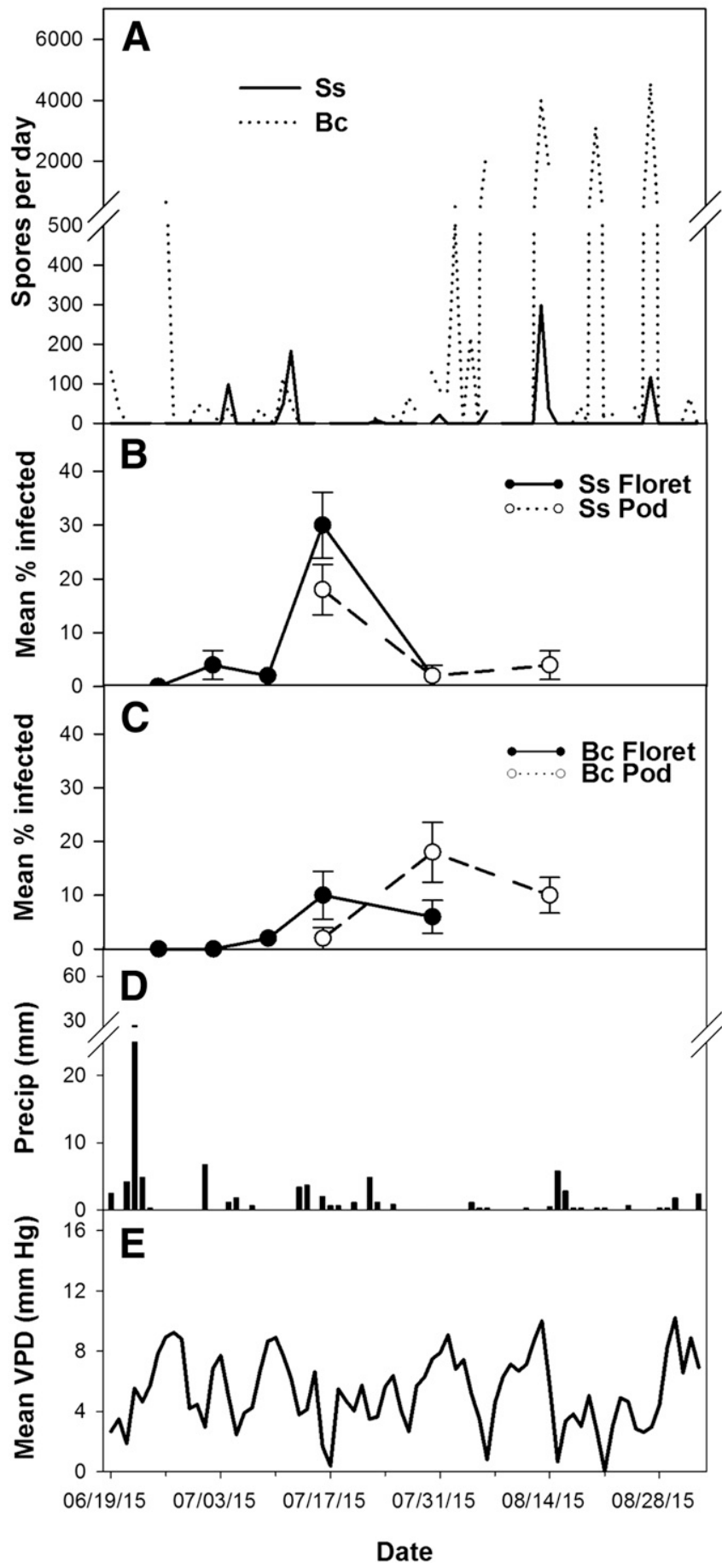

Fig. 2. Temporal discharge of A, Sclerotinia sclerotiorum (Ss) ascospores and Botrytis cinerea (Bc) conidia quantified by quantitative (real-time) polymerase chain reaction; $\mathbf{B}$ and $\mathbf{C}$, incidence of pathogens on florets and pods surface disinfested and plated on Sclerotinia semiselective medium and Botrytis semiselective medium; and $\mathbf{D}$ and $\mathbf{E}$, associated precipitation and vapor deficit levels in the North Rosemary field over two growing seasons. 
blossom blight of seed alfalfa conducted in Manitoba and Saskatchewan. In particular, Gossen and Platford (1999) found that, in Saskatchewan, incidence of $B$. cinerea increased from early to late bloom; in Manitoba, however, B. cinerea incidence peaked at midbloom and was very low at late bloom. For $S$. sclerotiorum, the patterns in both Saskatchewan and Manitoba followed the patterns detected here; namely, a gradual decrease in incidence from early to late bloom. These patterns indicate that $B$. cinerea is more prevalent during the pod stage, corresponding to conidia levels measured by the spore samplers and qPCR assay (Figs. 1 to 3). The Botrytis spp. isolated from florets and pods showed a much greater diversity in field populations than previously thought, though the importance of this diversity on the progression of blossom blight is unclear. B. prunorum has only been characterized in Japanese plum (Ferrada et al. 2016) and its pathogenicity on alfalfa is unknown. In all, $40 \%$ of the isolates had an unresolved species identification, and sequencing more regions would help clarify the lineages and, perhaps, delineate new species or isolates. That only $40 \%$ of the field Botrytis isolates collected from florets and pods were identified as $B$. cinerea may have several implications for blossom blight management. First, because the qPCR assay only quantified $B$. cinerea DNA, the spore values presented here could underestimate the true disease pressure

\section{Enchant 2014}

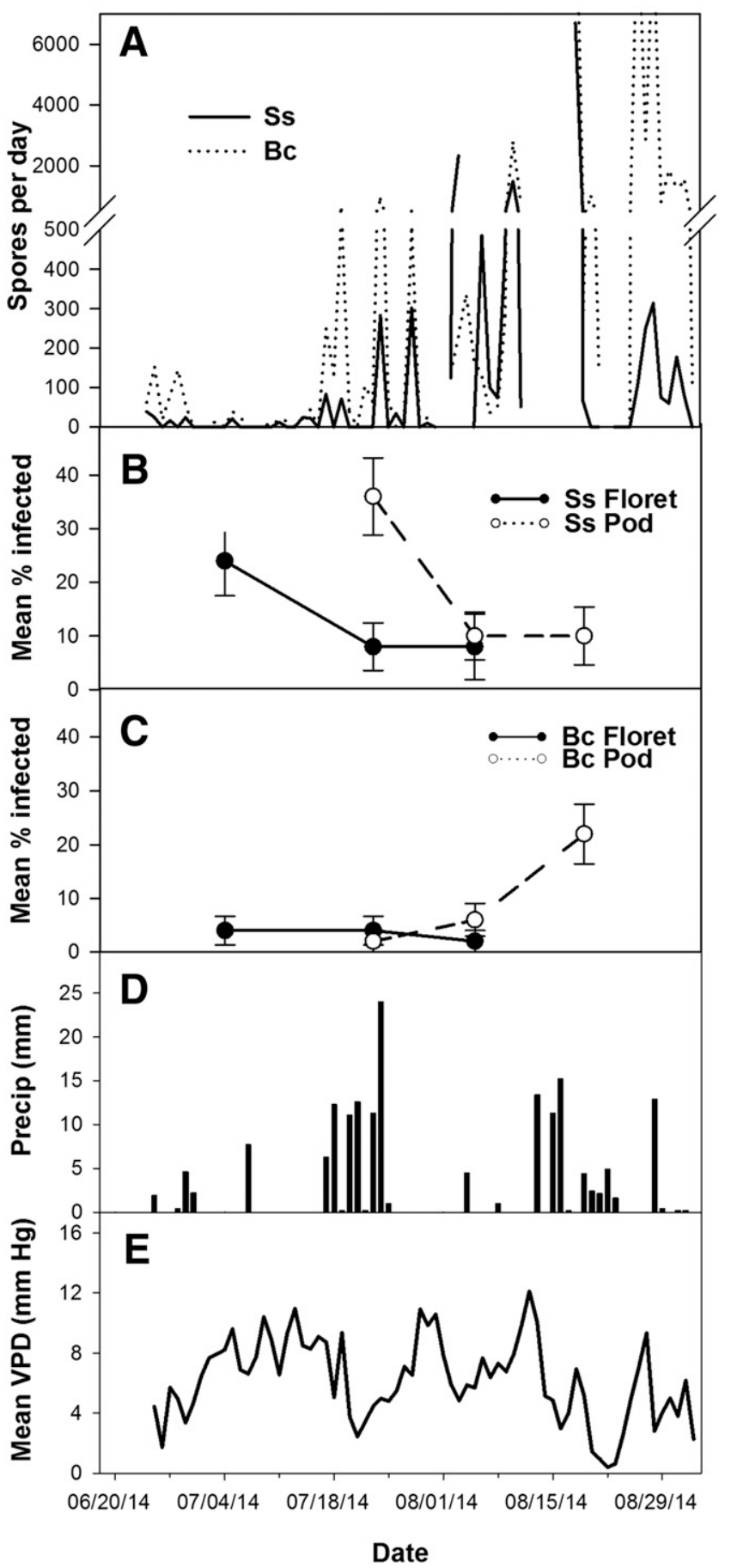

S. Rosemary 2015

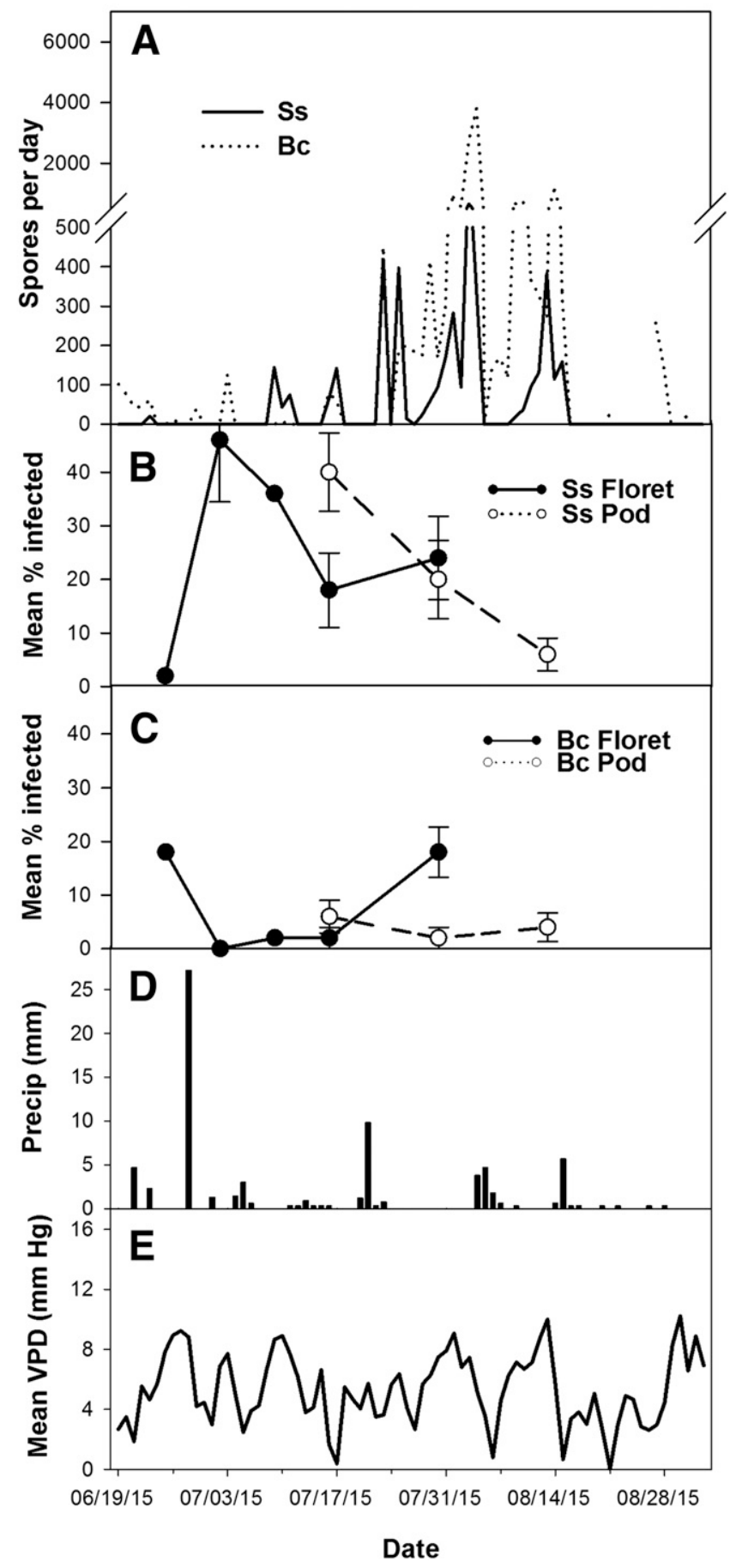

Fig. 3. Temporal discharge of A, Sclerotinia sclerotiorum (Ss) ascospores and Botrytis cinerea (Bc) conidia quantified by quantitative (real-time) polymerase chain reaction; $\mathbf{B}$ and $\mathbf{C}$, incidence of pathogens on florets and pods surface disinfested and plated on Sclerotinia semiselective medium and Botrytis semiselective medium; and D and $\mathbf{E}$, associated precipitation and vapor deficit levels in the Enchant field for 2014 and South Rosemary field for 2015. 
in the field. Second, these results show that the pathogen community in seed alfalfa fields is more diverse than previously thought, and that biological differences between species could have important implications in the disease cycle if these other species are found to be pathogenic to alfalfa. Third, discrepancies between plate culture and molecular identification methods highlight the importance of continued surveillance efforts to monitor changes in the composition of pathogen populations-particularly because Botrytis. and Sclerotinia spp. are well characterized to develop resistance to fungicides (Amiri et al. 2013, 2014; Jo et al. 2008; Leroux et al. 2002). The latter point also reveals the importance of a disease forecasting program, which could contribute to more prudent use of fungicides as part of the sustainable management of blossom blight.

According to plated floret and pod results, S. sclerotiorum incidence was greatest during the flower stage and early pod stage (Table 3; Figs. 1 to $3 \mathrm{~B}$ and $\mathrm{C}$ ) but, according to aerosol samples analyzed by qPCR, the majority of $S$. sclerotiorum inoculum was detected toward the end of the flowering stage and well into the pod stage (Figs. 1 to 3A). These same patterns were reported in canola fields near Edmonton, Alberta, Canada, where plant infection peaked in early July and ascospore occurrence peaked in late July and August (Williams and Stelfox 1980). In field surveys, signs of $S$. sclerotiorum were only evident at later stages of crop development (surveys completed in late July and early August) although, as described previously, the overall incidence of blossom blight was low. These findings are comparable with other crops susceptible to infection by $S$. sclerotiorum (e.g., dry bean and canola), in which disease surveys are typically performed just prior to maturity (early August to early September, depending on the season),

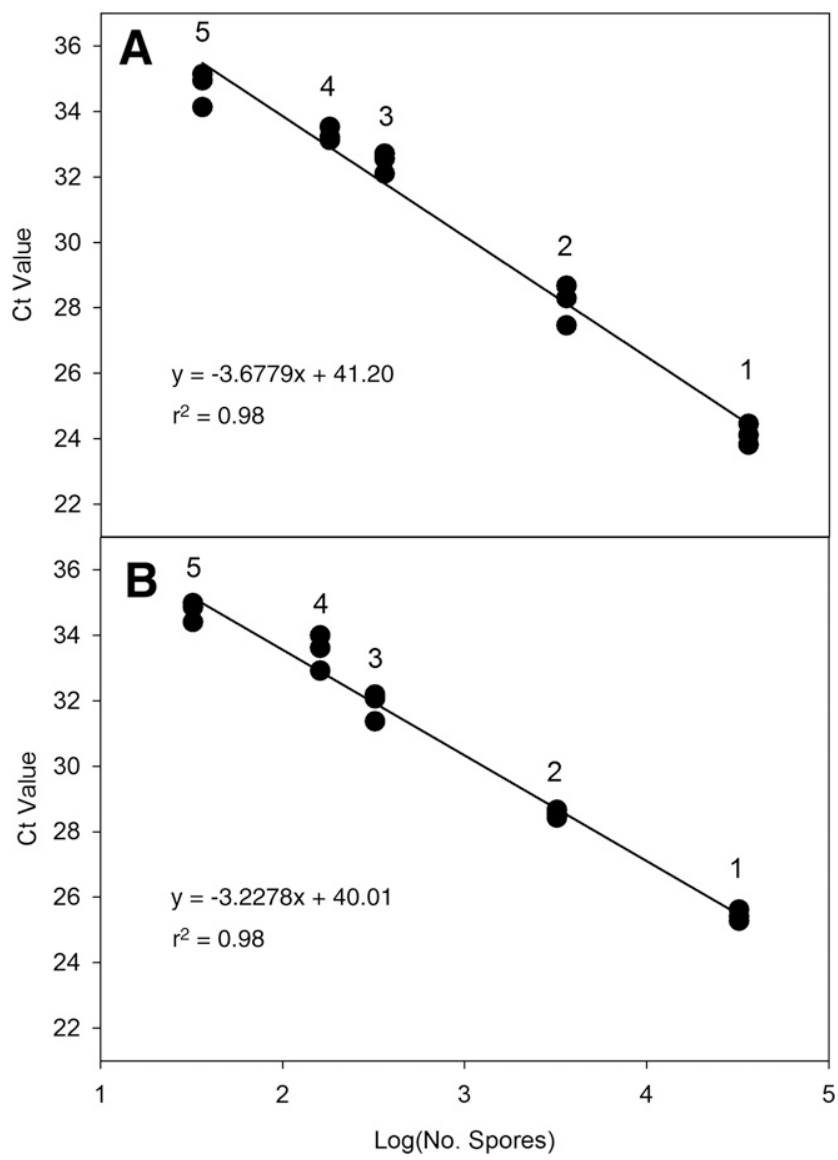

Fig. 4. Typical standard curves of A, Sclerotinia sclerotiorum ascospores and B, Botrytis cinerea conidia. Ascospores and conidia were serially diluted prior to DNA extraction, and the DNA from three replicates were pooled for each point on the standard curve. $\mathrm{Ct}=$ cycle threshold. A, Points are representative of DNA extracted from (1) $3.6 \times 10^{4}$, (2) $3.6 \times 10^{3}$, (3) $3.6 \times 10^{2}$, (4) $1.8 \times 10^{2}$, and (5) 36 ascospores. Efficiency $=87.0 \%$. B, Points are representative of DNA extracted from (1) $3.2 \times 10^{4}$, (2) $3.2 \times 10^{3}$, (3) $3.2 \times 10^{2}$, (4) $1.6 \times 10^{2}$, and (5) 32 conidia. Efficiency $=104.8 \%$. when disease intensity is greatest (Balasubramanian et al. 2014; Dokken-Bouchard et al. 2010; Huang et al. 1988).

Disease expression is the result of a combination of different events, including spore dispersal, infection initiation, and disease progression, each of which may have unique environmental requirements for completion. The results presented here indicate that spore dispersal is favored by dryer conditions, and much previous work shows that the infection process requires high $\mathrm{RH}$ or free moisture (Cole et al. 1996; Doss et al. 1993; Reich et al. 2015). Previous field surveys have shown that diseases caused by blossom blight pathogens only become severe under cool, very wet conditions in the latter part of the growing season (Gossen and Platford 1999; Turkington et al. 1991). Thus, although spore levels of both blossom blight pathogens were high in August, the hotter, dryer conditions in the 2 years were not conducive to infection. As a corollary, the higher floret and pod infection by $S$. sclerotiorum in early July could be explained by an overall wetter, cooler environment during the early part of the growing season.

Results from the current study highlight some of the difficulties involved in aerosol sampling protocols and the often contradictory evidence relating to horizontal and vertical spatial distributions of, in particular, $S$. sclerotiorum. Like conidia of $B$. cinerea, ascospores of $S$. sclerotiorum are ubiquitous, and field populations rarely seem to follow a clear temporal pattern of spore release (Bourdôt et al. 2001; Parker et al. 2014; Qandah and del Río Mendoza 2011). Many studies have shown that, unlike B. cinerea, incidence of S. sclerotiorum tends to be spatially clustered (Boland and Hall 1988; Hao and Subbarao 2005; Qandah and del Rio Mendoza 2012), with ascospore dispersal exhibiting a steep concentration gradient from their source (Bourdôt et al. 2001). On the other hand, others have shown that ascospore dispersal may occur over long distances (Bourdôt et al. 2001; Williams and Stelfox 1979). These somewhat conflicting results have led to contrasting views on the relative importance of longrange dispersal of ascospores. For example, Gugel (1986) concluded that this inoculum plays a significant role in disease progress, while others (Bourdôt et al. 2001; Twengström et al. 1998) concluded the

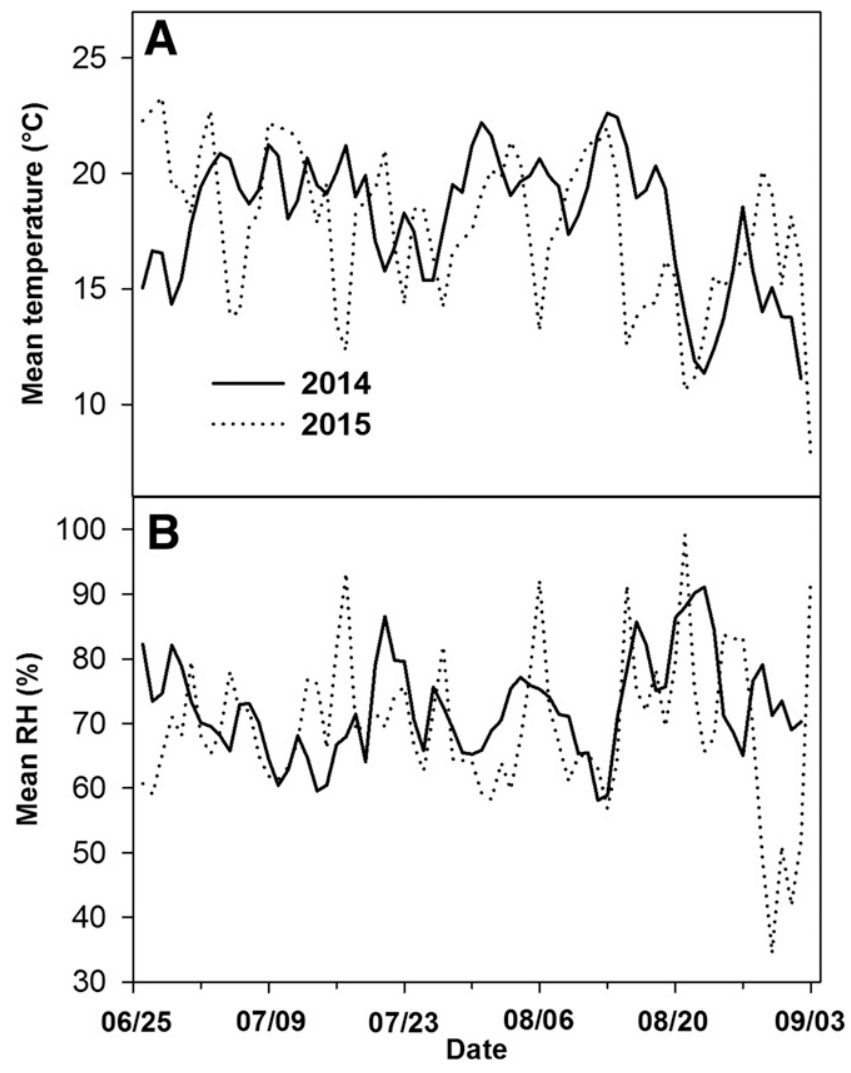

Fig. 5. A, Mean daily temperature and B, relative humidity (RH) in the 2014 and 2015 growing seasons. Data points are mean values calculated from data recorded by infield weather stations in three alfalfa seed fields. 
opposite. Thus, the implication of extra field sources of $S$. sclerotiorum or B. cinerea inoculum on disease development requires some clarification.

Airborne monitoring studies to date tend to employ only one spore sampler per field, whose position, in light of aggregated distribution of $S$. sclerotiorum in the field, is unlikely representative of the field. We are unaware of any studies that have empirically assessed the vertical distribution of ascospores, though some modeling approaches have explicitly included canopy structure in their simulations (de Jong et al. 2002). Previous studies have placed agar plates or the orifice of a spore sampler at or just above the canopy; however, given the spatially aggregated distribution of $S$. sclerotiorum under field conditions (Boland and Hall 1988; Hao and Subbarao 2005; Qandah and del Rio Mendoza 2012) and the potential difficulties associated with ascospores escaping a dense canopy (de Jong et al. 2002), the majority of released ascospores may not escape the canopy; as a result, this placement of sampling devices could be a poor strategy.
Ascospore movement restricted by the canopy could explain why, in the present study, floret infection by $S$. sclerotiorum was high at the beginning of the season, even though the number of ascospores quantified was low. The greater number of ascospores quantified in the latter half of the growing season could be related to apothecia maturation near the spore samplers, inoculum from outside the field, or environmental and physical conditions that favored apothecia germination followed by spore production, release, and dispersal. For instance, a large discharge of ascospores (2,265 ascospores/day) was found in Rosemary 2 days after a hailstorm destroyed most of the foliage in that field, which lends support to the idea that the dense foliage prevents ascospores from escaping the canopy. Although, overall, both species followed similar discharge patterns, there were some noticeable dates where one was detected in excess while the other was not detected at all (e.g., 10 and 26 August 2014 in North Rosemary; Fig. 2), and the mechanisms underlying these differences have yet to be elucidated.

Table 4. Summary of the multiple logistic regression models determined by forward stepwise selection and minimum Bayesian Information Criterion for Spore Y/N for each field-year data set and for Sclerotinia sclerotiorum and Botrytis cinerea

\begin{tabular}{|c|c|c|}
\hline Year, field & Variables in final model ${ }^{a}$ & $\mathbf{A U} \mathbf{C}^{\mathbf{b}}$ \\
\hline \multicolumn{3}{|c|}{ S. sclerotiorum ascospores $\mathrm{Y} / \mathrm{N}$} \\
\hline \multicolumn{3}{|c|}{2014} \\
\hline Enchant & DiffRH_2d, RH80_0d & 0.6908 \\
\hline North Rosemary & RH2hMin_2d, RH3hMin_1d & 0.8006 \\
\hline \multicolumn{3}{|l|}{2015} \\
\hline Brooks & DiffRH_1d, RH3hMax_0d & 0.8253 \\
\hline South Rosemary & RH70_1d, ET_2d, MinT_1d & 0.9052 \\
\hline North Rosemary & MinT_2d, RH3hMin_1d, MaxT_2d, AveT_2d & 0.9270 \\
\hline All field-years ${ }^{\mathrm{c}}$ & DiffRH_1d & 0.7116 \\
\hline \multicolumn{3}{|l|}{ B. cinerea conidia $\mathrm{Y} / \mathrm{N}$} \\
\hline \multicolumn{3}{|l|}{2014} \\
\hline Enchant & RH70_2d, MaxT_2d, RH3hMin_1d & 0.8587 \\
\hline North Rosemary & DiffVPD_1d & 0.7083 \\
\hline \multicolumn{3}{|l|}{2015} \\
\hline Brooks & RH3hMax_0d, DiffRH_1d, DiffVPD_Od & 0.7668 \\
\hline South Rosemary & DelVPD3_0d, RH3hMin_Od, RH2hMin_1d, DelVPD5_1d & 0.8550 \\
\hline North Rosemary & DelRH10_1d & 0.6125 \\
\hline All field-years ${ }^{c}$ & RH2hMin_1d, RH2hMax_2d & 0.6853 \\
\hline
\end{tabular}

${ }^{\text {a }}$ For descriptions of variables, refer to Table 2.

$\mathrm{b}$ Area under the receiver operating characteristic curve.

c Includes data from Brooks in 2014.

Table 5. Summary of the multiple logistic regression models determined by forward stepwise selection and minimum Bayesian Information Criterion for Spore $>100$ for each field-year data set and for Sclerotinia sclerotiorum and Botrytis cinerea

\begin{tabular}{|c|c|c|}
\hline Year, field & Variables in final model ${ }^{\mathbf{a}}$ & $\mathbf{A U C} \mathbf{C}^{\mathbf{b}}$ \\
\hline \multicolumn{3}{|c|}{ S. sclerotiorum ascospores $>100$} \\
\hline \multicolumn{3}{|c|}{2014} \\
\hline Enchant & PrecipY/N_1d, RH70_2d, VPDMin_0d, RH70_0d & 0.8929 \\
\hline North Rosemary & DPMin_2d, ET_1d & 0.8673 \\
\hline \multicolumn{3}{|l|}{2015} \\
\hline Brooks & VPDMin_2d, DiffRH_1d & 0.9061 \\
\hline South Rosemary & RH90_0d, DiffVPD_0d, VPD6_2d & 0.8879 \\
\hline North Rosemary & PrecipY/N_0d, DelVPD2_0d & 0.8043 \\
\hline All field-years ${ }^{\mathrm{c}}$ & DiffRH_1d & 0.6130 \\
\hline \multicolumn{3}{|l|}{ B. cinere conidia $>100$} \\
\hline \multicolumn{3}{|l|}{2014} \\
\hline Enchant & VPD6_0d, RH2hMax_1d, RH2hMax_2d & 0.7832 \\
\hline North Rosemary & DelVPD_2d, RH3hMin_2d & 0.7913 \\
\hline \multicolumn{3}{|l|}{2015} \\
\hline Brooks & DiffRH_1d, RH3hMax_0d & 0.7710 \\
\hline South Rosemary & RH3hMin_1d & 0.6970 \\
\hline North Rosemary & DiffVPD_1d, DelVPD2_0d & 0.7655 \\
\hline All field-years ${ }^{\mathrm{c}}$ & DiffRH_1d & 0.6516 \\
\hline
\end{tabular}

\footnotetext{
${ }^{a}$ For descriptions of variables refer to Table 2.

${ }^{\mathrm{b}}$ Area under the receiver operating characteristic curve.

${ }^{\mathrm{c}}$ Includes data from Brooks in 2014.
} 
The numbers of $B$. cinerea and $S$. sclerotiorum spores quantified in the present study are comparable with other aerobiological studies. For B. cinerea, previous work in strawberry (Xu et al. 2000) and raspberry (Jarvis 1962) found maximum daily conidia discharge from $10^{3}$ and $10^{4}$, respectively, which is similar to our findings of a daily maximum of $2 \times 10^{4}$ conidia. In raspberry, the daily number of conidia collected remained close to zero for most of July but increased steadily throughout August, with massive discharge events on 11 and 18 August (Jarvis 1962). Similar trends were observed in the three alfalfa fields surveyed in both years, which had low conidia numbers until the end of July, followed by several large discharge events throughout August. These findings are consistent with the knowledge that $B$. cinerea is a polycyclic pathogen (Williamson et al. 2007), releasing conidia whenever conditions are conducive. As the season progresses, it is expected that the discharges of conidia become greater as disease development and inoculum levels increase exponentially.

For S. sclerotiorum, previous work in canola found maximum daily ascospore discharge in the $10^{3}$ range, with significant variation between years dependent on Precip levels (Qandah and del Río Mendoza 2011). In one year, the maximum discharge occurred on 24 June, at the beginning of the canola flowering, and remained low over the rest of the season. In another year, however, ascospore discharge began at the end of June and continued at high $\left(10^{2}\right.$ to $\left.10^{3}\right)$ levels throughout the flowering period until the end of July. Because S. sclerotiorum is only capable of producing inoculum once per season, this seemingly continuous presence of ascospores may suggest that heterogeneity in microclimates and isolate preferences result in a staggered maturation of apothecia and ascospore release. Similar continuous discharge patterns and magnitudes were observed for ascospore levels in canola fields and sunflower fields in England (McCartney and Lacey 1991; Rogers et al. 2009) and in pasture fields in New Zealand (Bourdôt et al. 2001). In the present study, most fields exhibited relatively constant ascospore discharge throughout July and August. However, in 2014, North Rosemary appeared to follow the more typical pattern of a monocyclic pathogen, with one concentrated period of ascospore release at the beginning of August (Fig. 3).

Comparisons with inoculum threshold values determined in other studies are difficult to make due to differences in sampling methodology and inoculum quantification. Typically, inoculum in other studies is reported as spores per cubic meter or spores per cubic meter per day. In onion, threshold values for conidia of B. squamosa were determined at 10 and 15 conidia $\mathrm{m}^{-3}$ (Carisse et al. 2005). The equivalent of $2.5 \mathrm{~m}^{3}$ day $^{-1}$ was sampled in these studies, and this would translate to threshold values of 25 and 37.5 conidia day $^{-1}$. If those criteria were applied to B. cinerea spores in the present study, 168 and 153 days, respectively, would have been identified as peak spore days over all fields and seasons, compared with 115 peak spore days determined by the cutoff of 100 conidia reported here. Studies of ascospore discharge in carrot and canola provide a broader range of threshold values. In carrot, researchers sampled $3 \mathrm{~m}^{3}$ each day and determined thresholds of 2 and 9.5 ascospores $\mathrm{m}^{-3}$, or roughly 6 and 28.5 ascospores day ${ }^{-1}$ (Parker et al. 2014). Applied to S. sclerotiorum ascospores in the present study, these threshold values would have predicted 92 and 127 peak spore days over all fields and seasons, compared with 47 peak spore days determined by the cutoff of 100 ascospores reported here. In canola, investigators arbitrarily decided on a threshold value of 20 ascospores $\mathrm{m}^{-3}$ day $^{-1}$ (approximately 290 ascospores day ${ }^{-1}$ ) to separate high-discharge days from low-discharge days (Qandah and del Río Mendoza 2011). This threshold value would have predicted 25 peak spore release days if applied to the current study.

In contrast to disease development models for B. cinerea (Broome et al. 1995; Xu et al. 2000) or carpogenic germination models for $S$. sclerotiorum (Clarkson et al. 2007; Foster et al. 2011; Sun and Yang 2000), comparatively few attempts have been made to develop statistical models for spore release for Sclerotinia and Botrytis spp. Previous attempts at models of spore release for Sclerotinia and Botrytis spp. have varied in their predictive abilities and have found markedly different environmental variables driving spore release. Sudden or dramatic changes in $\mathrm{RH}$ have been associated with spore release in both B. cinerea and $S$. fructicola (Jarvis 1962; Tate 1979); maximum T associated with spore release in $B$. cinerea (Hartill 1980); and hot, dry conditions following moist conditions favorable for apothecia and ascospore development hypothesized to favor ascospore release by $S$. sclerotiorum (Turkington et al. 1991). In general, our results are consistent with these findings, which suggest that spore release is a response to an environmental stress or sudden change. More sophisticated statistical techniques such as autoregressive integrated moving average (ARIMA) approaches have had success in predicting the numbers of $B$. cinerea conidia in the air over the course of a growing season (Fernandez-Gonzalez et al. 2012; Rodríguez-Rajo et al. 2010). In contrast to the previously described models, these ARIMA models determined that conidia release was highly correlated with Precip or DP 2 days before and RH 3 or 4 days before the sporulation day. In canola, high RH values over a period of 5 to 7 days were associated with ascospore release by $S$. sclerotiorum (Qandah and del Río Mendoza 2011).

When data from all fields and years were analyzed in a stepwise logistic regression, the notable result was that three of the four resulting models identified the same single-variable model for the prediction of conidia and ascospore occurrence. Subsequently, this variable (the difference between maximum and minimum $\mathrm{RH}$ of the preceding day) was plotted against the log (number of spores) for randomly selected fields and spore types and appeared to correlate well with spore discharge, especially in the latter half of the season (data not shown). This finding may be a result of generally low frequency and magnitude of sporulation events in the first half of the season, or it may indicate that spore release is limited by changes in $\mathrm{RH}$ in the latter half of the season and by some other factors in the former half. However, this finding also suggests that the magnitude of change in $\mathrm{RH}$ is the most important predictor of both conidia and ascospore release under the climatic conditions of southern Alberta. The simplicity of this single-variable model is attractive because $\mathrm{RH}$ is an easy environmental variable to monitor and, thus, will be used as the starting point for future modeling and prediction systems for these pathogens.

One of the main limitations with many of the published models based on airborne spore concentrations is that few have established the threshold level of spores above which economic losses accrue. Empirically determining these thresholds is a procedure that has been done relatively rarely (Carisse et al. 2005) but is an important next step to complete before a disease forecasting model for blossom blight pathogens can become useful to seed alfalfa growers. Furthermore, consideration of environmental conditions leading to carpogenic germination and apothecia development as a prerequisite for ascospore release should be included in a systems modeling approach for infection by $S$. sclerotiorum. The work presented here is an important first step toward accomplishing this goal, and could be transferable to other crops grown in the region that are also susceptible to blossom blight pathogens, such as Sclerotinia stem rot of canola.

\section{Acknowledgments}

We thank the funders, the Alberta Crop Industry Development Fund (ACIDF), and the Alfalfa Seed Commission Alberta (ASCA) for contributing to this research; the seed alfalfa producers who allowed us access to their fields; many students, especially B. Leyland, A. Seeley, and K. Pinto-Larsen, without whose help this work could not have been completed; and R. Kroebel for his insights and advice on modelling.

\section{Literature Cited}

AAFC. 2015. 2014 Annual Review of Agroclimate Conditions Across Canada Drought Watch. Government of Canada, Ottawa, ON, Canada.

AAFC. 2016. 2015 Annual Review of Agroclimate Conditions Across Canada Drought Watch. Government of Canada, Ottawa, ON, Canada.

Adams, P. B., and Ayers, W. A. 1979. Ecology of Sclerotinia species. Phytopathology 69:896-899.

Almquist, C., and Wallenhammar, A.-C. 2015. Monitoring of plant and airborne inoculum of Sclerotinia sclerotiorum in spring oilseed rape using real-time PCR. Plant Pathol. 64:109-118.

Amiri, A., Heath, S. M., and Peres, N. A. 2013. Phenotypic characterization of multifungicide resistance in Botrytis cinerea isolates from strawberry fields in Florida. Plant Dis. 97:393-401.

Amiri, A., Heath, S. M., and Peres, N. A. 2014. Resistance to fluopyram, fluxapyroxad, and penthiopyrad in Botrytis cinerea from strawberry. Plant Dis. 98:532-539. 
An, H. R., Mainelis, G., and White, L. 2006. Development and calibration of realtime PCR for quantification of airborne microorganisms in air samples. Atmos. Environ. 40:7924-7939.

Anders, S., and Huber, W. 2010. Differential expression analysis for sequence count data. Genome Biol. 11:R106.

Balasubramanian, P. M., Conner, R. L., McLaren, D. L., Chatterton, S., and Hou, A. 2014. Partial resistance to white mould in dry bean. Can. J. Plant Sci. 94: 683-691.

Bardin, S. D., and Huang, H. C. 2001. Research on biology and control of Sclerotinia diseases in Canada. Can. J. Plant Pathol. 23:88-98.

Boland, G. J., and Hall, R. 1988. Relationships between the spatial pattern and number of apothecia of Sclerotinia sclerotiorum and stem rot of soybean. Plant Pathol. 37:329-336.

Bourdôt, G. W., Hurrell, G. A., Saville, D. J., and DeJong, D. M. D. 2001. Risk analysis of Sclerotinia sclerotiorum for biological control of Cirsium arvense in pasture: Ascospore dispersal. Biocontrol Sci. Technol. 11:119-139.

Brooker, S., Hay, S. I., and Bundy, D. A. P. 2002. Tools from ecology: Useful for evaluating infection risk models? Trends Parasitol. 18:70-74.

Broome, J. C., English, J. T., Marois, J. J., Latorre, B. A., and Aviles, J. C. 1995. Development of an infection model for Botrytis bunch rot of grapes based on wetness duration and temperature. Phytopathology 85:97-102.

Carisse, O., McCartney, H. A., Gagnon, J. A., and Brodeur, L. 2005. Quantification of airborne inoculum as an aid in the management of leaf blight of onion caused by Botrytis squamosa. Plant Dis. 89:726-733.

Carisse, O., Tremblay, D. M., Levesque, C. A., Gindro, K., Ward, P., and Houde, A. 2009. Development of a TaqMan real-time PCR assay for quantification of airborne conidia of Botrytis squamosa and management of Botrytis leaf blight of onion. Phytopathology 99:1273-1280.

Clarkson, J. P., Fawcett, L., Anthony, S. G., and Young, C. 2014. A model for Sclerotinia sclerotiorum infection and disease development in lettuce, based on the effects of temperature, relative humidity and ascospore density. PLoS One 9:e94049.

Clarkson, J. P., Phelps, K., Whipps, J. M., Young, C. S., Smith, J. A., and Watling, M. 2007. Forecasting Sclerotinia disease on lettuce: A predictive model for carpogenic germination of Sclerotinia sclerotiorum sclerotia. Phytopathology 97:621-631.

Clarkson, J. P., Staveley, J., Phelps, K., Young, C. S., and Whipps, J. M. 2003. Ascospore release and survival in Sclerotinia sclerotiorum. Mycol. Res. 107: 213-222.

Cole, L., Dewey, F. M., and Hawes, C. R. 1996. Infection mechanisms of Botrytis species: Pre-penetration and pre-infection processes of dry and wet conidia. Mycol. Res. 100:277-286.

Coley-Smith, J. R., and Cooke, R. C. 1971. Survival and germination of fungal sclerotia. Annu. Rev. Phytopathol. 9:65-92.

CSGA. 2014. 2014 Canadian Seed Growers' Association (CSGA) November Acreage and Membership Report: Canadian Seed Growers' Association, Ottawa, ON, Canada.

de Jong, M. D., Bourdôt, G. W., Powell, J., and Goudriaan, J. 2002. A model of the escape of Sclerotinia sclerotiorum ascospores from pasture. Ecol. Modell. 150: 83-105.

Diguta, C. F., Rousseaux, S., Weidmann, S., Bretin, N., Vincent, B., GuillouxBenatier, M., and Alexandre, H. 2010. Development of a qPCR assay for specific quantification of Botrytis cinerea on grapes. FEMS Microbiol. Lett. 313:81-87.

Dillies, M.A., Rau, A., Aubert, J., Hennequet-Antier, C., Jeanmougin, M., Servant, N., Keime, C., Marot, G., Castel, D., Estelle, J., Guernec, G., Jagla, B., Jouneau, L., Laloe, D., Le Gall, C., Schaeffer, B., Le Crom, S., Guedj, M., and Jaffrezic, F. on behalf of The French StatOmique Consortium. 2013. A comprehensive evaluation of normalization methods for Illumina high-throughput RNA sequencing data analysis. Brief. Bioinf. 14:671-683.

Dokken-Bouchard, F. L., Bassendowski, K. A., Boyle, T., Cowell, L. E., Gugel, R. K., Ippolito, J., Kirkham, C. L., Kutcher, H. R., Lewchuk, Z., Miller, S. G., Morrall, R. A. A., and Phelps, S. 2010. Survey of canola diseases in Saskatchewan, 2009. Can. Plant Dis. Surv. 90:127-129.

Doss, R. P., Potter, S. W., Chastagner, G. A., and Christian, J. K. 1993. Adhesion of nongerminated Botrytis cinerea conidia to several substrata. Appl. Environ. Microbiol. 59:1786-1791.

Edwards, S. G., and Seddon, B. 2001. Selective media for the specific isolation and enumeration of Botrytis cinerea conidia. Lett. Appl. Microbiol. 32:63-66.

Fernandez-Gonzalez, M., Rodriguez-Rajo, F. J., Jato, V., Aira, M. J., Ribeiro, H., Oliveira, M. B., and Abreu, I. 2012. Forecasting ARIMA models for atmospheric vineyard pathogens in Galicia and Northern Portugal: Botrytis cinerea spores. Ann. Agric. Environ. Med. 19:255-262.

Ferrada, E. E., Latorre, B. A., Zoffoli, J. P., and Castillo, A. 2016. Identification and characterization of Botrytis blossom blight of Japanese plums caused by Botrytis cinerea and B. prunorum sp. nov. in Chile. Phytopathology 106:155-165.

Foroud, N. A. 2011. Investigating the molecular mechanisms of Fusarium head blight resistance in wheat. Ph.D. thesis, University of British Columbia, Vancouver, BC, Canada.

Foster, A. J., Kora, C., McDonald, M. R., and Boland, G. J. 2011. Development and validation of a disease forecast model for Sclerotinia rot of carrot. Can. J. Plant Pathol. 33:187-201.

Frank, G. 2003. Alfalfa Seed and Leafcutter Bee Production and Marketing Manual. Irrigated Alfalfa Seed Producers Association, Brooks, AB, Canada.
Gossen, B. D., Holley, J. D., Harrison, L. M., and Smith, S. R. 1998. Distribution of blossom blight of alfalfa in western Canada and impact on seed yield. Can. J. Plant Pathol. 20:122.

Gossen, B. D., Lan, Z., Harrison, L. M., Holley, J., and Smith, S. R. 1997. Survey of blossom blight of alfalfa on the Canadian Prairies in 1996. Can. Plant Dis. Surv. 77:89-90.

Gossen, B. D., and Platford, G. 1999. Blossom blight in alfalfa seed fields in Saskatchewan and Manitoba 1998. Can. Plant Dis. Surv. 79:95-96.

Greiner, M., Pfeiffer, D., and Smith, R. D. 2000. Principles and practical application of the receiver-operating characteristic analysis for diagnostic tests. Prev. Vet. Med. 45:23-41.

Gugel, R. K. 1986. Inoculum-disease relationships in Sclerotinia stem rot of rapeseed in Saskatchewan. Can. J. Plant Pathol. 8:89-96.

Gutierrez, W. A., and Shew, H. D. 1998. Identification and quantification of ascospores as the primary inoculum for collar rot of greenhouse-produced tobacco seedlings. Plant Dis. 82:485-490.

Hao, J. J., and Subbarao, K. V. 2005. Comparative analyses of lettuce drop epidemics caused by Sclerotinia minor and S. sclerotiorum. Plant Dis. 89:717-725.

Hartill, W. F. T. 1980. Aerobiology of Sclerotinia sclerotiorum and Botrytis cinerea spores in New Zealand tobacco crops. N. Z. J. Agric. Res. 23:259-262.

Hind-Lanoiselet, T. L., Lanoiselet, V. M., Lewington, F. K., Ash, G. J., and Murray, G. M. 2005. Survival of Sclerotinia sclerotia under fire. Australas. Plant Pathol. 34:311-317.

Hospodsky, D., Yamamoto, N., and Peccia, J. 2010. Accuracy, precision, and method detection limits of quantitative PCR for airborne bacteria and fungi. Appl. Environ. Microbiol. 76:7004-7012.

Huang, H. C., Acharya, S. N., and Erickson, R. S. 2000. Etiology of alfalfa blossom blight caused by Sclerotinia sclerotiorum and Botrytis cinerea. Plant Pathol. Bull. 9:11-16.

Huang, H. C., Kokko, M. J., and Phillippe, L. M. 1988. White mold of dry bean (Phaseolus vulgaris L.) in southern Alberta, 1983-87. Can. Plant Dis. Surv. 68:11-13.

Huang, H. C., and Kozub, G. C. 1989. A simple method for the production of apothecia from sclerotia of Sclerotinia sclerotiorum. Plant Prot. Bull. 31:333-345.

Inch, S., Fernando, W. G. D., and Gilbert, J. 2005. Seasonal and daily variation in the airborne concentration of Gibberella zeae (Schw.) Petch spores in Manitoba. Can. J. Plant Pathol. 27:357-363.

Jarvis, W. R. 1962. The dispersal of spores of Botrytis cinerea Fr. in a raspberry plantation. Trans. Br. Mycol. Soc. 45:549-559.

Jiménez-Valverde, A. 2012. Insights into the area under the receiver operating characteristic curve (AUC) as a discrimination measure in species distribution modelling. Glob. Ecol. Biogeogr. 21:498-507.

Jo, Y. K., Chang, S. W., Boehm, M., and Jung, G. 2008. Rapid development of fungicide resistance by Sclerotinia homoeocarpa on turfgrass. Phytopathology 98:1297-1304.

Klosterman, S. J., Anchieta, A., McRoberts, N., Koike, S. T., Subbarao, K. V., Voglmayr, H., Choi, Y. J., Thines, M., and Martin, F. N. 2014. Coupling spore traps and quantitative PCR assays for detection of the downy mildew pathogens of spinach (Peronospora effusa) and beet (P. schachtii). Phytopathology 104: 1349-1359.

Lang-Yona, N., Dannemiller, K., Yamamoto, N., Burshtein, N., Peccia, J., Yarden, O., and Rudich, Y. 2012. Annual distribution of allergenic fungal spores in atmospheric particulate matter in the Eastern Mediterranean: A comparative study between ergosterol and quantitative PCR analysis. Atmos. Chem. Phys. 12:2681-2690.

Leroux, P., Fritz, R., Debieu, D., Albertini, C., Lanen, C., Bach, J., Gredt, M., and Chapeland, F. 2002. Mechanisms of resistance to fungicides in field strains of Botrytis cinerea. Pest Manage. Sci. 58:876-888.

Luo, Y., Ma, Z., Reyes, H. C., Morgan, D., and Michailides, T. J. 2007. Quantification of airborne spores of Monilinia fructicola in stone fruit orchards of California using real-time PCR. Eur. J. Plant Pathol. 118:145-154.

McCartney, H. A., and Lacey, M. E. 1991. The relationship between the release of ascospores of Sclerotinia sclerotiorum, infection and disease in sunflower plots in the United Kingdom. Grana 30:486-492.

Nair, N. G., and Allen, R. N. 1993. Infection of grape flowers and berries by Botrytis cinerea as a function of time and temperature. Mycol. Res. 97: 1012-1014

Neath, A. A., and Cavanaugh, J. E. 2012. The Bayesian information criterion: Background, derivation, and applications. WIREs Comput. Stat. 4:199-203.

Olivier, C. Y., Gossen, B. D., and Séguin-Swartz, G. 2008. Impact of flower age and colour on infection of bean and alfalfa by Sclerotinia sclerotiorum. Can. J. Plant Pathol. 30:58-65.

Parker, M. L., McDonald, M. R., and Boland, G. J. 2014. Evaluation of air sampling and detection methods to quantify airborne ascospores of Sclerotinia sclerotiorum. Plant Dis. 98:32-42.

Pearce, J., and Ferrier, S. 2000. Evaluating the predictive performance of habitat models developed using logistic regression. Ecol. Modell. 133:225-245.

Peccia, J., and Hernandez, M. 2006. Incorporating polymerase chain reaction-based identification, population characterization, and quantification of microorganisms into aerosol science: A review. Atmos. Environ. 40:3941-3961.

Qandah, I. S., and del Río Mendoza, L. E. 2011. Temporal dispersal patterns of Sclerotinia sclerotiorum ascospores during canola flowering. Can. J. Plant Pathol. 33:159-167. 
Qandah, I. S., and del Rio Mendoza, L. E. 2012. Modelling inoculum dispersal and Sclerotinia stem rot gradients in canola fields. Can. J. Plant Pathol. 34:390-400.

Reich, J., and Chatterton, S. 2015. Blossom blight and stem rot of seed alfalfa in southern Alberta in 2014. Can. Plant Dis. Surv. 95:147-148.

Reich, J., Chatterton, S., and Johnson, D. 2015. Potential role of pollen and pollinators in the spread of blossom blight of seed alfalfa caused by Botrytis cinerea. Can. J. Plant Pathol. 37:465-475.

Reich, J. D., Alexander, T. W., and Chatterton, S. 2016. A multiplex PCR assay for the detection and quantification of Sclerotinia sclerotiorum and Botrytis cinerea. Lett. Appl. Microbiol. 62:379-385.

Rodríguez-Rajo, F. J., Jato, V., Fernández-González, M., and Aira, M. J. 2010. The use of aerobiological methods for forecasting Botrytis spore concentrations in a vineyard. Grana 49:56-65.

Rogers, S. L., Atkins, S. D., and West, J. S. 2009. Detection and quantification of airborne inoculum of Sclerotinia sclerotiorum using quantitative PCR. Plant Pathol. 58:324-331.

Samac, D. A., Rhodes, L. H., and Lamp, W. O. 2015. Compendium of Alfalfa Diseases and Pests. American Phytopathological Society, St. Paul, MN.

Staats, M., van Baarlen, P., and van Kan, J. A. 2005. Molecular phylogeny of the plant pathogenic genus Botrytis and the evolution of host specificity. Mol. Biol. Evol. 22:333-346.

Sun, P., and Yang, X. B. 2000. Light, temperature, and moisture effects on apothecium production of Sclerotinia sclerotiorum. Plant Dis. 84:1287-1293.

Suarez, M. B., Walsh, K., Boonham, N., O'Neill, T., Pearson, S., and Barker, I. 2005. Development of real-time PCR (TaqMan) assays for the detection and quantification of Botrytis cinerea in planta. Plant Physiol. Biochem. 43: 890-899.

Sutton, J. C., Swanton, C. J., and Gillespie, T. J. 1978. Relation of weather variables and host factors to incidence of airborne spores of Botrytis squamosa. Can. J. Bot. 56:2460-2469.

Swets, J. A. 1988. Measuring the accuracy of diagnostic systems. Science 240: 1285-1293.

Tate, K. G. 1979. Sclerotinia fructicola ascospore fluctuations in a peach orchard during blossom. N. Z. J. Agric. Res. 22:355-360.
Thuiller, W., Araujo, M. B., and Lavorel, S. 2003. Generalized models vs classification tree analysis: Predicting spatial distributions of plant species at different scales. J. Veg. Sci. 14:669-680.

Turkington, T. K., and Morrall, R. A. A. 1993. Use of petal infestation to forecast Sclerotinia stem rot of canola: The influence of inoculum variation over the flowering period and canopy density. Phytopathology 83:682-689.

Turkington, T. K., Morrall, R. A. A., and Rude, S. V. 1991. Use of petal infestation to forecast Sclerotinia stem rot of canola: the impact of diurnal and weatherrelated inoculum fluctuations. Can. J. Plant Pathol. 13:347-355.

Twengström, E., Sigvald, R., Svensson, C., and Yuen, J. 1998. Forecasting Sclerotinia stem rot in spring sown oilseed rape. Crop Prot. 17:405-411.

Wagner, A. O., Praeg, N., Reitschuler, C., and Illmer, P. 2015. Effect of DNA extraction procedure, repeated extraction and ethidium monoazide (EMA)/ propidium monoazide (PMA) treatment on overall DNA yield and impact on microbial fingerprints for bacteria, fungi and archaea in a reference soil. Appl. Soil Ecol. 93:56-64.

West, J. S., Atkins, S. D., Emberlin, J., and Fitt, B. D. 2008. PCR to predict risk of airborne disease. Trends Microbiol. 16:380-387.

West, J. S., and Kimber, R. B. E. 2015. Innovations in air sampling to detect plant pathogens. Ann. Appl. Biol. 166:4-17.

Williams, J. R., and Stelfox, D. 1979. Dispersal of ascospores of Sclerotinia sclerotiorum in relation to Sclerotinia stem rot of rapeseed. Plant Dis. Rep. 63:395-399.

Williams, J. R., and Stelfox, D. 1980. Occurrence of ascospores of Sclerotinia sclerotiorum in areas of central Alberta. Can. Plant Dis. Surv. 60:51-54.

Williamson, B., Duncan, G. H., Harrison, J. G., Harding, L. A., Elad, Y., and Zimand, G. 1995. Effect of humidity on infection of rose petals by dryinoculated conidia of Botrytis cinerea. Mycol. Res. 99:1303-1310.

Williamson, B., Tudzynski, B., Tudzynski, P., and van Kan, J. A. 2007. Botrytis cinerea: The cause of grey mould disease. Mol. Plant Pathol. 8:561-580.

Xu, X.-M., Butt, D. J., and Ridout, M. S. 1995. Temporal patterns of airborne conidia of Podosphaera leucotricha, causal agent of apple powdery mildew. Plant Pathol. 44:944-955.

Xu, X.-M., Harris, D. C., and Berrie, A. M. 2000. Modeling infection of strawberry flowers by Botrytis cinerea using field data. Phytopathology 90:1367-1374. 